\title{
CIGB-300 Synthetic Peptide, an Antagonist of CK2 Kinase Activity, as a Treatment for Covid-19. A Computational Biology Approach
}

\section{Jamilet Miranda ( $\nabla$ jamilet.miranda@cigb.edu.cu )}

Center for Genetic Engineering and Biotechnology: Centro de Ingenieria Genetica y Biotecnologia https://orcid.org/0000-

0002-9601-1745

\section{Ricardo Bringas}

Center for Genetic Engineering and Biotechnology: Centro de Ingenieria Genetica y Biotecnologia

\section{Jorge Fernandez-de-Cossio}

Center for Genetic Engineering and Biotechnology: Centro de Ingenieria Genetica y Biotecnologia

\section{Yasser Perera-Negrin}

Center for Genetic Engineering and Biotechnology: Centro de Ingenieria Genetica y Biotecnologia

\section{Research Article}

Keywords: CIGB-300, SARS-CoV-2, phosphoproteomics, CK2 inhibitor, Computational biology, Covid-19 treatment, NPM1/B23, SQSTM1, SRSF1, HSBP1

Posted Date: August 30th, 2021

DOI: https://doi.org/10.21203/rs.3.rs-795492/v1

License: (c) (i) This work is licensed under a Creative Commons Attribution 4.0 International License. Read Full License 


\section{Abstract}

Background: Similarities in the hijacking mechanisms used by SARS-CoV-2 and several type of cancer, suggest the repurposing of cancer drugs to treat Covid-19. CK2 kinase antagonists have been proposed for the treatment of cancer. A recent study in cells infected with SARS-CoV-2 virus found a significant CK2 kinase activity, and the use of a CK2 inhibitor showed antiviral responses. CIGB-300, originally designed as an anticancer peptide, is an antagonist of CK2 kinase activity that binds to CK2 phospho-acceptor sites. Recent preliminary results show an antiviral activity of CIGB-300 versus a surrogate model of coronavirus. Here we present a computational biology study that provides evidences at the molecular level of how CIGB-300 might interfere with SARS-CoV-2 life cycle inside infected human cells.

Methods: Sequence analysis and phosphorylation studies data were combined to predict infection-induced molecular mechanism that can be interfered by CIGB-300. Next we integrated multi-omics data on SARS-CoV-2 infection and data on the antagonistic effect on CK2 kinase activity of CIGB-300 to predict the potential benefits of its treatment in COVID-19 patients. A combination of network and functional enrichment analysis was used.

Results: First, from SARS-CoV studies, we infer the potential incidence of CIGB-300 in SARS-CoV-2 interference on immune response. Next, from the analysis of multiple Omics data, we propose the action of CIGB-300 since early stage of viral infections perturbing the virus hijacking of RNA splicing machinery. It was also predicted the interference of CIGB-300 in virushost interactions responsible for the high infectivity and the particular immune response to SARS-CoV-2 infection. Further, we provide evidences of CIGB-300 attenuation of phenotypes related to muscle, bleeding, coagulation and respiratory disorders.

Conclusions: We have evidenced the potential benefits of using CIGB-300 to treat COVID-19 patients and strongly suggest its use since early stages of viral infection.

\section{Introduction}

SARS-CoV-2 currently spread world-wide showing high infectivity and transmissibility. Due to the urgency of finding effective therapeutics treatments in the shortest possible time, drug repurposing emerged as the first option $(1,2)$. The huge amount of data so far generated permit the re-consideration of drugs already evaluated for other diseases, which might have advanced toxicological, preclinical and/or clinical studies.

Since the genomic sequence of SARS-CoV-2 was made available in January 2020 (3), diversity of technique and laboratory models has been profusely applied to the study of SARS-CoV-2 replication and infectivity.

Blanco-Mello et al. (4) performed RNA-seq experiments from polyA RNAs isolated from infected cells. They found a diminished transcriptional response of type I/III interferon-induced genes and, concurrently, a significant increase of chemokines and IL6, which ground their suggestion to evaluate FDA-approved drugs with immunomodulating properties that could be rapidly implemented in clinical protocols.

Various mass-spectrometry studies made important contribution to the comprehension of SARS-CoV-2 life cycle. Gordon et al. (5) using affinity-purification mass spectrometry (AP-MS) identified the sets of human proteins that physically interact with each of 26 viral proteins that they previously individually cloned in human cells derived from kidney HEK-293T/17. A total of 332 physical interactions between SARS-CoV-2 and human proteins were identified. When the expressions of all interacting human proteins in 29 different tissues were analyzed, lung was identified as the one with the highest expression levels. GO enrichment analysis was performed to the set of human interactors of each viral protein cloned. For each of the 26 sets, the major overrepresented biological processes included Nuclear Transport, Ribonucleoprotein Complex Biogenesis and Cellular Component Disassembly. Host proteins involved in innate immune response were targeted by viral proteins nsp13, nsp15 and orf9b while proteins from the Nf-kB pathway were targeted by nsp13 and orf9c. The most relevant host proteins targeted by known drugs were identified from this analysis. Next, they demonstrated the capacity of some of these drugs to reduce viral infectivity. The study of Gordon et al. (5) is of outstanding relevance for the understanding of the mechanism used by SARS-

Page $2 / 23$ 
CoV-2 to improve its infectivity and to avoid a strong immune response. It also provides valuable information for repurposing of existing drugs.

The role of kinases in the course of viral infection was addressed by Bouhaddou et al. (6), who carried a quantitative mass spectrometry-based phosphoproteomics study in Vero E6 cells infected by SARS-CoV-2. Casein kinase II (CK2) and p38 MAP kinases were significantly activated while mitotic kinases were shutdown. A relevant role of CK2 in induced filopodia protrusions during viral infection was evidenced in association with viral capsid protein N. Both CK2 and protein N were colocalized in filopodia protrusions which were significantly longer and more branched than in control cells. The authors suggest that $\mathrm{N}$ protein may control CK2 activity and regulate cytoskeleton elements in filopodia. Although the role of CK2 in viral infections is not new, it is remarkable the level of upregulation of CK2 activity as consequence of SARS-CoV-2 infection (6). The strong antiviral activity of Silmitasertib (CX-4945), a CK2 inhibitor, suggests this kinase as an attractive target for treating Covid-19 patients. Ongoing clinical trial of CX-4945 is evaluating its clinical benefits and anti-viral activities in moderate COVID-19 patients (7).

CIGB-300 is a synthetic peptide designed to bind the phospho-acceptor motif of CK2 substrates, interfering the phosphorylation of serine/threonine residues by CK2. Clinical use of CIGB-300 have confirmed it safety and tolerability when administered intravenously showing clinical efficacy in cancer patients $(8,9)$.

In a phosphoproteomic experiment in $\mathrm{NCl}-\mathrm{H} 125$ cells, Perera et al. (10) identified CK2 phospho-acceptors peptides that are significantly inhibited by CIGB-300. They found for the first time, that CIGB-300 binds CK2a subunit and impairs CK2a2 $\beta 2$ holoenzyme enzymatic activity. By contrast, phosphorylation of CK2 $\beta$ subunit, which contains itself a consensus CK2 phosphorylation motif, was not influenced by CIGB-300. Additionally, Perera et al. (11) identified nucleophosmin (B23) as a major target of CIGB-300. Of note, Nouri et al. (12) further reported the binding of CIGB-300 to B23 oligomerization domain. This interaction blocks the association of B23 to Rev and US11 proteins, two functionally homologous proteins from HIV and HSV viruses respectively. Cells treated with CIGB-300 showed a significant reduction of virus production suggesting B23 as an attractive target for antiviral drugs. Lobaina and Perera (13) also proposed B23 as a potential target in antiviral therapies.

With this background, CIGB-300 was tested for its safety and clinical benefits in Covid-19 patients in a phase I/II clinical trial (14). It reduced the number of pulmonary lesions among treated individuals. Additionally, CIGB-300 antiviral effect on MDBK cell infected with bovine coronavirus (BCoV) Mebus was explored (15). CIGB-300 inhibited the cytopathic effect and reduced the viral protein accumulation in the cytoplasm. Physical interaction of CIGB-300 with BCoV nucleocapsid protein $(\mathrm{N})$ was also revealed. Functional enrichment found cytoskeleton reorganization and protein folding as the major disturbed biological processes.

Here we present an in silico analysis of SARS-CoV and SARS-CoV-2 viral infection. We performed a multi-omics integrative analysis of SARS-CoV-2 infection of human cell lines that combines functional enrichment and network representation. At the level of phosphorylation sites, we integrated data from four different phosphoproteomics studies on SARS-Cov-2 infection (6, 16-18) and one study on CIGB-300 inhibition of kinase activity (10). We identified biological processes and virus activated phosphosites at different times after viral infection that can be interfered by CIGB-300. Our results are consistent with the benefits already evidenced of CIGB-300 treatment in Covid-19 patients.

\section{Material And Methods}

\section{Public Data}

Protein sequence information was downloaded from UniprotKB database (19) https://www.uniprot.org/.

Data sources from phosphoproteomics studies of host and viral proteins of SARS-CoV-2 infected human cell lines were downloaded from site listed in Table 1. 
Table 1

SARS-CoV-2 infection phosphoproteomics studies data sources.

\begin{tabular}{|llll|}
\hline Reference & Timepoints & $\begin{array}{l}\text { Cell } \\
\text { lines }\end{array}$ & Downloaded from: \\
\hline $\begin{array}{l}\text { Bouhaddou et } \\
\text { al. (6) }\end{array}$ & $\begin{array}{l}\text { 2h,4h,8h,12h } \\
\text { and 24h }\end{array}$ & $\begin{array}{l}\text { Vero } \\
\text { E6 }\end{array}$ & http://dx.doi.org/10.17632/dpkbh2g9hy.1 \\
\hline $\begin{array}{l}\text { Hekman et al. } \\
(16)\end{array}$ & $\begin{array}{l}\text { 1h,3h,6h and } \\
24 h\end{array}$ & iAT2 & https://www.ebi.ac.uk/pride/archive/projects/PXD020183 \\
\hline $\begin{array}{l}\text { Stukalov et al. } \\
(18)\end{array}$ & 6h and 24h & A549 & https://www.nature.com/articles/s41586-021-03493-4\#MOESM5 \\
\hline $\begin{array}{l}\text { Klann et al. } \\
(17)\end{array}$ & $24 h$ & $\begin{array}{l}\text { CaCo- } \\
2\end{array}$ & $\begin{array}{l}\text { https://www.cell.com/molecular-cell/fulltext/S1097-2765(20)30549- } \\
\text { 9\#supplementaryMaterial }\end{array}$ \\
\hline
\end{tabular}

The phosphorylation data of CIGB-300 treatment from Perera et al. (10) were downloaded from https://link.springer.com/article/10.1007\%2Fs11010-020-03747-1\#additional-information/.

Protein expression data from Bojkova et al. (20) were downloaded from http://corona.papers.biochem2.com/.

A total of 332 humand-SARS-CoV-2 PPIs from Gordon et al. (5) were downloaded from Biogrid database (21) at https://thebiogrid.org/225737/publication/comparative-host-coronavirus-protein-interaction-networks-reveal-pan-viraldisease-mechanisms.html\#!.

Information of CK2 Substrates was downloaded from PhosphoSitePlus at (https://www.phosphosite.org/) (22).

\section{Data Analysis}

Sequence alignments were performed with the desktop version of CLUSTALX multiple sequence alignment program (23).

Analysis of proteomics data from Bojkova et al. (20) was carried out with MEV (24). SAM method (25) for two-class unpaired comparison was used to identify most differentially expressed proteins as implemented in MEV. Parameter delta was set so that the estimated median number of false significant proteins would be cero.

For Bouhaddou et al. (6), Stukalov et al. (18), Klann et al. (17) and Hekman et al. (16) data on phosphorylation induced by SARS-CoV-2 infection, the criteria for choosing differentially phosphorylated sites was $\log _{2}$ fold change $>=0.25$ and adjustedp-value $<=0.05$, the same values proposed by Hekman et al. (16).

The phosphorylation changes induced by CIGB-300 treatment were extracted from Perera et al. (10). All inhibitions reported by the authors at 10 and/or 30 minutes were considered.

For Gene Set Enrichment Analysis we used GSEA version 4.1.0 for windows (26-28). Ordered gene lists for each time point after infection were provided as input. The pre-ranked gene list option was used for databases containing REACTOME and GO biological process gene sets. MSigdb v7.2 gmt files were downloaded from: http://www.gsea-

msigdb.org/gsea/downloads.jsp. In this case, the criteria used for the statistical significance was a Nominal p-value threshold of 0.05 and a False Discovery Rate (FDR) of 0.25 , as recommended by the GSEA software.

Cytoscape tool $(29,30)$ was used to build and merge networks in Figs. 7 and 8.

BisoGenet CytoScape plugin (31), available from CytoScape Application Manager, was used to generate protein-protein interaction (PPI) networks.

Venn Diagrams were generated using web application in http://bioinformatics.psb.ugent.be/. 
Functional analysis of enriched pathways and reactions was performed using Reactome Pathway Knowledgebase (32) at: https://reactome.org/. The criteria used for selection was FDR $<=0.05$.

GeneCodis 4.0, at https://genecodis.genyo.es/, was used for diseases enrichment analysis (33). Data sources for Human Phenotypes HPO and OMIM were both consulted individually and integrated. The results were obtained in form of networks clusters.

BiNGO plugin (34), available from Cytoscape Application Manager, was used to determine and visualize Gene Ontology (GO) categories statistically overrepresented.

Additional statistical analysis and graphs were generated and plotted using GraphPad Prism version 5.00 software (GraphPad Software, San Diego, CA, USA).

\section{Results}

\section{Inferring the potential effect of CIGB-300 treatment on SARS-CoV-2 virus infection based in previous results.}

\section{CIGB-300 could alter N-protein localization and its RNA binding capacity}

A sequence alignment of $\mathrm{N}$ protein from SARS-CoV and SARS-CoV-2 viruses show a high similarity (Fig. 1). N Protein consists of two structural domains (Fig. 1): the N-terminal RNA-binding domain (RBD) (residues 41-186), and the C-terminal dimerization domain (residues 258-361). The rest of the protein is highly disordered (35).

Surjit et al. (37) predicted SARS-CoV N-protein to be heavily phosphorylated. Thr116 and Ser251 were noted as putative phospho-acceptors for CK2 (see Fig. 1), though neither has been corroborated experimentally. We collected a total of 33 phosphorylation sites for SARS-CoV-2 N protein (see Fig. 1 and Additional file 1: Table S1) from four recent mass spectrometry studies $(6,16,17,36)$. Davidson et al. (36) reported two putative CK2 sites at Ser2 and Ser78. Hekman et al. (16) found Ser23 and Ser410 to be phosphorylated by CK2.

Bouhaddou et al. (6) analyzed the impact of phosphorylation in the N-protein surface charges by a 3D structural model of the RNA-binding domain. These changes may modulate the function of N-protein by regulating its RNA binding capacity. One of the phosphorylation sites responsible for these charge changes is the Ser78 (see Fig. 1), a CK2 phospho-acceptor site according to Davison et al. (36). Binding of CIGB-300 to Ser78 would interfere with N-protein RNA binding ability.

On the other hand, $\mathrm{N}$ protein is reported to be mainly located in the cytoplasm (37-39). However, a localization analysis of $\mathrm{N}$ expressing cells treated with four different phosphorylation inhibitors found a significant fraction of $\mathrm{N}$ protein localized in the nucleus of cells treated with CDK or CK2 inhibitors (37). Additionally, in cell infected by BCoV, CIGB-300 bound N protein, downregulated its expression and significantly reduced the accumulation of viral proteins in the cytoplasm(15).

Bouhaddou et al. (6) found CDK activity to be significantly reduced by SARS-CoV-2 infection while CK2 activity is significantly increased. Consequently, inhibition by CIGB-300 of N protein phosphorylation sites may alter, at least in part, its cytoplasmic localization. Hence, the use of CIGB-300 in Covid-19 patients would interfere the $\mathrm{N}$ protein role in viral cell cycle in infected cells as its function in particle assembly happens in cytoplasm.

\section{CIGB-300 could bind ORF6 C-terminus and restore IFNs signaling}

One important element of innate immune response to virus infections is the activation of antiviral genes as a consequence of interferon production. After activation of receptors by type I interferons, STAT1 is phosphorylated and forms a complex with STAT2 and IRF9 (40). This complex exposes a nuclear localization signal (NLS) that is bound by KPNA1, and as a last step before entering the nucleus KPNB1 binds KPNA1 and chaperons the complex through the nuclear pore (Fig. 2A) (41). 
Several groups have attributed an immune response antagonistic effect to Orf6 protein (41-43). In SARS-CoV experiments, Frieman et al. (41) reported that Orf6 interferes with host immune response by antagonizing STAT1 function. Orf6 binds karyopherin alpha 2 (KPNA2) and retains it in the ER/Golgi membrane. KPNB1 is also retained as it binds KPNA2. In this way, the chaperon function of KPNB1 through the nuclear pore is interfered, and STAT1 signaling is interrupted (Fig. 2B).

Frieman et al. (41) also found that the C-terminal 10 amino acids of SARS-CoV Orf6 are responsible for KPNA2 binding. In Fig. 3 we show the residues of Orf6 involved in the SARS-CoV mutants they generated, Orf $_{49-53 A l a}$, Orf6 $6_{54-58 A l a}$ and Orf6 ${ }_{59}$ 63Ala (author's nomenclature), by replacing amino acids 49-53, 54-58 and 59-63 with alanines, respectively. The last two mutants, Orf6 $6_{54-58 \mathrm{Ala}}$ and Orf6 ${ }_{59}$ - 63Ala, comprising the ten C-terminal amino acids, did not retain KPNA2 and as consequence, STAT1 function was unaffected. The first mutant Orf6 $_{49-53 A l a}$ was still able to retain KPNA2. So, the last ten aminoacids were responsible for KPNA2 binding and, as consequence, for KPNB1 recruitment.

Recently Lei et al. (44) carried a similar mutation study of SARS-CoV-2 Orf6 protein. They generated three different mutants; M1, M2 and M3 (author's nomenclature); by replacing aminoacids 49-52 (YSQL), 53-56 (DEEQ) and 57-61 (PMEID) by alanines, respectively (Orf6 of SARS-CoV-2 lacks the last two amino acids present in SARS-CoV protein). As expected, they obtained similar results: mutant M1 perturbs interferon stimulation as the wild type does, while mutants M2 and M3 lack the inhibitory effect.

In Fig. 3 we show an alignment of Orf6 protein sequences from SARS-CoV and SARS-CoV-2 viruses. The region between amino acids 50-53 with the sequence SELD in SARS-CoV protein and sequence SQLD in SARS-CoV-2, both match the CK2 substrate motif. Additionally, this site in SARS-CoV-2 was experimentally found to be phosphorylated, and predicted by computer analysis to be a phospho-acceptor site of CK2 (17). Ser50, as a CK2 phospho-acceptor site, could be bound by CIGB300. Mutant M2 of Lei et al. (44) include Asp53 residue at position + 3 relative to Ser50, and this position is known to be important for the recognition of CK2. Therefore, we strongly suggest that the possible binding of CIGB-300 to this phosphoacceptor motif would interfere the interaction of Orf6 C-terminus with KPNA2; avoiding its retention in the ER/Golgi membrane, without interfering KPNA2 chaperon activity of carrying STAT1 complex to the nucleus (Fig. 2C). In this regard, CIGB-300 could exhibit an effect that other CK2 antagonists that target CK2 won't.

\section{Interfering NUP98 hijacking by CIGB-300 via interaction with Orf6 C-terminus}

We analyzed proteomic expression data from Bojkova et al. (20) and found B23 exhibit the highest positive correlation with the expression profile of viral proteins (Additional file 2: Fig. S1). SARS-CoV virus N protein was found to interact with B23 protein (45). Despite that, Gordon et al. (5) did not reported a direct interaction of B23 with viral proteins. Looking for indirect interactions, we intersected the interactors of B23 with the 322 proteins found by Gordon et al. (5) to interact with viral proteins. A total of 21 host proteins resulted from this intersection, among which Nuclear Pore Complex protein 98 (NUP98) shown up as the only one that interact with Orf6, the viral protein with the highest expression correlation to B23.

Bouhaddou et al. (6) determined that phosphorylation at Ser888 of NUP98 increased during viral infection. The sequence around Ser888 is DSDEEE, which fulfills the phospho-acceptor motif of CK2. Additionally, Franchin et al. (46) found the phosphorylation of Ser888 to be altered by a CK2 inhibitor (according to data downloaded from PhosphositePlus web site). NUP98 is part of the Nuclear Pore Complex, responsible for the transport of biomolecules between the nucleus and cytoplasm. Bouhaddou et al. (6) suggested that the SARS-CoV-2 infection-induced phosphorylation of NUP98 may prevent export of mRNAs through the nuclear pore, a similar mechanism to those used by other viruses to increase the translation of viral RNA in the cytoplasm. Binding of CIGB-300 to Ser888 phospho-acceptor site of NUP98 could prevent its phosphorylation and restore host mRNA translocation to cytoplasm.

Also, Gordon et al. (5) found that Met58 and acidic residues Glu55, Glu59 and Asp61 are highly conserved in Orf6 homologs and are part of a putative NUP98/RAE binding motif. Miorin et al. (47) found that SARS-CoV-2 infection blocks the nuclear translocation of STAT1 and STAT2. Orf6 exerts this anti IFN-I activity by hijacking NUP98. Orf6 directly interact with NUP98 at 
the Nuclear Pore Complex(NPC) via its C-terminal end. A Met58Arg mutant in Orf6 C-terminal region impairs this interaction and abolish the IFN-I antagonistic effect (47).

The Orf6 interactions with KPNA2 and NUP98 have been both reported to interfere with IFN signaling. In both cases the Cterminal domain of Orf6 was responsible for the interaction, mutations in this region abolished the anti-IFN activity. The binding of CIGB-300 to the CK2 phospho-acceptor site Ser50 in Orf6 could impair the interaction with both KPNA2 and NUP98 and in some extend restore IFN signaling.

\section{CIGB-300 downregulate host proteins phosphosites consistently activated by SARS-CoV-2}

We now compare the phosphoproteomics studies of SARS-CoV-2 infection in Vero E6 (6), Caco-2 (17), iAT2 (16) and A549 (18) cell lines with that of Perera et al. (10) on CIGB-300 kinase antagonistic effect in H125.

First, we combined results of the four studies at the level of phosphorylation sites and found a total of 8642 different sites that were upregulated in at least one of the studies (Venn diagram in Fig. 4A). As noted by Hekman et al. (16), there are few proteins differentially regulated that coincide in all the four studies. Indeed, we found only six phosphosites that were upregulated by SARS-CoV-2 infection in the four cell lines.

Next, we intersected the data on SARS-CoV-2 infection with that of phosphorylation sites down regulated by the treatment of $\mathrm{H} 125$ cell line with CIGB-300, resulting in a total of 364 sites (see Fig. 4B). Of the six sites that were found upregulated in the four phosphoproteomics studies, half were downregulated by CIGB-300. These three sites, MATR3_S188, SQSTM1_S272 and DID01_S1456, have in common to have tens of Phosphorylation sites. We envisage that these three phospho-acceptor sites, can be targeted by a CIGB-300 treatment in Covid-19 patients.

MATR3 is a nuclear matrix protein with 36 phosphosites according to UniProt annotations. MATR3 plays multiple functions in DNA/RNA processing, it contains two RNA recognition Motifs and two Zinc Finger domains. It was proposed to stabilize mRNA species, to play a role in the regulation of DNA virus-mediated innate immune response (48) and to be associated to splicing regulation (49). In HIV-infected cells, Sarracino et al. (50) found MATR3 to be essential for RNA processing. MATR3 phoshorylation was found to greatly enhance its DNA binding ability $(51,52)$. It is well documented its implications in Amyotrophic lateral sclerosis (53), a disease causing muscle weakness and respiratory failures, symptoms common in Covid19 patients. CIGB-300 interference on virus-infection induced phosphorylation of MATR3 may play a role diminishing its effects in immune response attenuation and its implications in viral RNA processing.

SQSTM1 exhibit several phosphorylation sites, of these, Ser272 is the only one significantly activated by Sars-CoV-2 in the four phosphoproteomic studies. Zhang et al. (54) found that phosphorylation of SQSTM1 at Thr269 and Ser272 by MAPK13 promotes the microaggregates transport to the microtubule organizing center (MTOC) to form aggresomes which are later degraded through autophagy. Gao et al. (55) also showed that SQSTM1 phosphorylation increases its ability to sequester ubiquitinated proteins into aggresomes playing an important role in aggresome formation. Stukalov et al. (18) revealed significant reduction of autophagy flux by ORF3 which combined with the augmented microaggregates transport due to SQSTM1 phosphorylation conduces to the accumulation of aggresomes.

Several studies have reported the role of SQSTM1 accumulation and aggresome formation in lung related diseases. Tran et al. (56) demonstrated the role of aggresome formation induced by cigarette smoke in chronic obstructive pulmonary disease (COPD). They found a significant higher accumulation of SQSTM1 in smokers as compared to nonsmokers, and an increased severity of COPD. Wu et al. (57) found that the accumulation of SQSTM1 plays a critical role in airway inflammation induced by nanoparticles.

Cystic fibrosis (CF), is caused by mutations in the gene encoding the cystic fibrosis transmembrane conductance regulator (CFTR), which results in defective autophagy, causing the accumulation of CFTR containing aggregates (58). SQSTM1 
knockdown favoured the clearance of defective CFTR aggregates (59).

Inhibition by CIGB-300 of SQSTM1 phosphorylation at Ser272 may reduce the accumulation of aggresomes and this way attenuates lung inflammation and fibrosis induced by viral infection.

DID01 (death inducer-obliterator 1 or death-associated transcription factor DATF1) is a protein involved in apoptosis and have been also implicated in the progression of several type of cancer (60-63). DID01 possess 92 phosphosites, according to data we downloaded from Phosphosite. Of these sites we found 16 that match the CK2 phospho-acceptor motif described by Pinna (64). It is not clear the implications of DID01 in the course of viral infection, but it is known the induction of apoptosis by viral proteins and then DID01 may be activated by apoptosis pathway through phosphorylation. CIGB-300 may interfere this activation.

\section{CIGB-300 at early Stage of SARS-CoV-2 Infection}

We examine kinase activity from the earliest stages of the viral infection by analyzing phosphoproteomics data of Bouhaddou et al. (6) at $2 \mathrm{~h}$ and $4 \mathrm{~h}$ time points, and from Hekman et al. (16), at $1 \mathrm{~h}$ and $3 \mathrm{~h}$ time points.

GSEA analysis with proteins sets ranked by phosphorylation changes was performed to identify enriched REACTOME pathways. In Fig. 5A we show the plots of the normalized enrichment scores (NES) vs. FDR q-values and Nominal p-values of Reactome pathways. The most significant pathways (FDR $<5 \%$ ) at $1 \mathrm{~h}$ are predominantly down regulated (negative NES) while at $2 \mathrm{~h}$ and $3 \mathrm{~h}$ are up regulated (positive NES). Figure 5B shows the heat map of statistical significant pathways at each time point. After one hour of infection we observed a clear initial inhibition of host protein synthesis machinery, reflected in the inactivation of several phosphorylation sites of proteins involved in RNA metabolism events, such as "mRNA Splicing" and the "Pre-processing of capped intron containing mRNA" (Fig. 5B, light-green color in the heat map). This inactivation is reverted by the activation of these same biological events at $2 \mathrm{~h}$ and $3 \mathrm{~h}$ (Fig. 5B and 5E). The phosphosites listed are those belonging to proteins from the core enrichment set (CES) of each enriched pathway and those that were identified to be inactivated by CIGB-300 in Perera et al. (10). The Venn diagram in Fig. 5C shows the comparison of phosphosylation sites from proteins in "mRNA Splicing/Processing of capped intron containing pre-mRNA" pathway that were regulated at $1 \mathrm{~h}, 2 \mathrm{~h}, 3 \mathrm{~h}$ after infection or inhibited by CIGB300 action. Of those, SRSF1_S199 was the only site up-regulated at 2h and 3h. SRSF1_S201 was upregulated at $3 \mathrm{~h}$ as well as some other SRSF's proteins phosphosites (Fig. 5C). The interaction networks of proteins in these CESs for each time point are shown in Fig. 5D. SRSF proteins are highly connected and predominant in the three networks.

SRSFs are RBP splicing factors that belong to the family of S/R rich proteins. Rogan et al. (65) proposed a molecular mechanism for viral-RNA pulmonary infections based on protein expression and RBP binding site pattern analysis. They compared the distribution of RBP binding motifs in several viral genomes including SARS_CoV-2, Influenza A, HIV-1 and Dengue. These authors identified strong RBPs binding sites in SARS-CoV-2 genome. After infection, as the number of SARSCoV-2 genomes increase, the proportion of SRSFs bound to viral genome versus host transcriptome also increases. As the virus replicates in cytoplasm, newly synthetized SRSF1 molecules are bound by viral RNA and retained there, resulting in the formation of R-loops in the nucleus due to a reduction of RBP import. Rogan et al. (65) suggested that R-loop induced apoptosis could contribute to the spreading of viral particles to neighboring pneumocytes causing a deterioration of lung functions.

Phosphorylation plays an important role in SRSF proteins function. SRPK1 kinase was shown to phosphorylate multiple serine residues in SR rich domain of SRSF1 $(66,67)$, promoting its nuclear import where it plays an important role in RNA stability (68) and alternative splicing (69). CK2 was found to be the major kinase that phosphorylate SRPK1 and this phosphorylation occurs mainly at Ser51 and Ser555, resulting in 6-fold activation of the enzyme (70). After SARS-CoV-2 infection of AT2 cell, Ser51 is activated at $3 \mathrm{~h}$ and $6 \mathrm{~h}(16)$.

Figure 6 show the expression profile of CK2 and the levels of phosphorylation of SRPK1 S51 site, according to data from Hekman et al. (16). A clear correlation is observed between the amount of CK2 kinase and the phosphorylation activation of 
this phospho-acceptor site, an additional argument supporting the role of CK2 on the activation of SRPK1 during SARS-CoV-2 infection.

These results are consistent with previous reports predicting an extensive reshaping of splicing pathways by SARS-CoV-2 infection $(17,20)$. SRSF1 is an important element of this splicing machinery that is clearly used by SARS-CoV-2 for its own replication and translation.

The increasing amount of SRSF1 bound to viral genome as the infection progress is a clear indication of its role in viral RNA processing. Phosphorylation is an important mechanism that control SRSF1 function.

Taking all these together, we suggest that CIGB-300 intervene SRSF1 role in SARS-CoV-2 protein synthesis interfering its phosphorylation by SRPK1 kinase.

\section{Infection-induced protein-protein interactions could be perturbed by CIGB-300}

Next, we compared the host-viral PPIs reported by Gordon et al. (5) with phosphoproteomic data from Perera et al. (10) on the identification of CK2 substrates significantly inhibited by the CIGB-300. Figure 7 show virus-host interactions from Gordon et al. (5) in which host proteins contain phospho-acceptor sites that were inhibited by CIGB-300 treatment (highlighted in yellow). In this network several proteins are relate to RNA processing and transcription (LARP1, LARP7, LARP4B), supporting the results already mentioned. Binding of CIGB-300 to phospho-acceptor sites of host proteins inhibiting its phosphorylation may perturb the binding by viral proteins and consequently the viral life cycle.

Evaluating how CIGB-300 may interfere host-host protein interactions implicated in virus-induced mechanisms, we found that 68 proteins (SC2_300 set from now on) have activated phospho-acceptor sites in at least two of the four phosphoproteomic studies, which were inhibited by CIGB-300 (see Additional file 3: Table S2). The PPI network built with these proteins is shown in Fig. 8. A majority of the nodes in the network are interconnected indicating potential functional relations among them of biological significance. Proteins are grouped by mRNA metabolism, Cell Cycle, and Selective Autophagy pathways, identified as significant by a Reactome enrichment analysis (see Additional file 4: Table S3). The five proteins with higher degree are also highlighted. Among them are HNRNPA1, HSPB1, SRRM2, and SRRM1, which are implicated in mRNA metabolism, corroborating the potential impact of CIGB-300 in viral replication and transcription. The fifth protein was B23/NPM1, identified as a major target of CIGB-300 in cancer cells, but also as a relevant target for antiviral therapies (11-13).

In this network HSPB1 heat shock protein (alias HSP27) is one of the highest degree nodes. HSPB1 was found to be overexpressed in idiopathic pulmonary fibrosis (IPF) patients. It activates pro-fibrotic mechanisms and consequently has been suggested as a target to treat IPF $(71,72)$. In tumor cells, Ivermectin inhibits the phosphorylation of Ser78 and Ser82 of HSP27, while Ser15 is only slightly inhibited (73). Also Ivermectin have shown to be on inhibitor of SARS-CoV-2 with a significant reduction of viral RNA levels $(74)$ and increase the clinical recovery of mild and severe Covid-19 patients $(75,76)$. SARS-CoV-2 activates HSPB1 Ser15 and Ser82 during infection while CIGB-300 inhibits both phospho-acceptor sites (10). This is an additional argument in favor of using CIGB-300 in Covid-19 patients aiming to reduce pulmonary lesions as it was evidenced in a phase I/II clinical trial (14).

\section{Human phenotypes involving kinase activity induced by SARS-CoV-2, potentially targeted by CIGB-300}

We build a network with the top 20 human phenotypes most enriched in the set SC2_300, using GeneCodis tool (see Fig. 9 and Additional file 5: Table S4). The network can be divided in two main subnetworks, one related to muscular disorder phenotypes that include Paralysis, Distal muscle weakness, Rimmed Vacuoles, Mildly elevated creatine kinase and Fatigue. The second subnetwork groups phenotypes related to respiratory(Exertional dyspnea, difuse alveolar hemorraghe), bleeding (Metrorrhagia, oral cavity bleeding) and coagulation disorders(Disseminated intravascular coagulation). 
The phenotypes in the first subnetwork are all associated to HNRNPA1, MATR3 and SQSTM1 genes, and have been also reported as Covid-19 symptoms (77-81). For example, elevated creatine kinase levels is associated to a poor outcome prediction (77) and persistent fatigue is a common symptom in Covid-19 patients (80). As we mentioned MATR3 and SQSTM1 possess phosphosites that were activated in all four phosphoproteomic studies we analyzed, and HNRNPA1 was the node with the highest degree in the PPI network built. Rimmed Vacuoles, the most significant of the enriched phenotypes, are found in areas of destruction of muscle fibers. Fatigue phenotype is located somewhere in the interface between the two subnetworks and is connected to the three genes mentioned, and also to the three genes that are in the core of the second subnetwork: B23/NPM1, FIP1L1 and NUMA1. The phenotypes in the second subnetwork have been all identified in Covid-19 patients $(82,83)$.

Table 2

Summary of main findings.

\begin{tabular}{|c|c|c|c|c|c|}
\hline Analysis Type & Subject & Identity & Working Hypothesis & Experimental Clues & Reference \\
\hline $\begin{array}{l}\text { Individual CK2 } \\
\text { sites }\end{array}$ & $\begin{array}{l}\text { Viral } \\
\text { proteins }\end{array}$ & $\mathrm{N}$ & $\begin{array}{l}\text { CK2 phosphosite } \\
\text { inhibition/blockage } \\
\text { by CIGB-300 impairs } \\
\text { viral replication and } \\
\text { IFN signaling }\end{array}$ & $\begin{array}{l}\text { Interaction, co- } \\
\text { localization, N } \\
\text { mRNA and protein } \\
\text { expression } \\
\text { inhibition by CIGB- } \\
300 \text { in a subrogate } \\
\text { model }\end{array}$ & $(15)$ \\
\hline $\begin{array}{l}\text { Individual CK2 } \\
\text { sites }\end{array}$ & $\begin{array}{l}\text { Viral } \\
\text { proteins }\end{array}$ & ORF6 & $\begin{array}{l}\text { CK2 phosphosite } \\
\text { inhibition/blockage } \\
\text { by CIGB-300 impairs } \\
\text { IFN signaling }\end{array}$ & $\begin{array}{l}\text { Additive/Synergistic } \\
\text { profile of CIGB-300 } \\
\text { plus IFN alpha }\end{array}$ & Unpublished \\
\hline $\begin{array}{l}\text { Co-Expression } \\
\text { and network } \\
\text { propagation }\end{array}$ & $\begin{array}{l}\text { Host } \\
\text { and } \\
\text { Viral } \\
\text { Proteins }\end{array}$ & NUP98, ORF6, B23 & $\begin{array}{l}\text { CK2 phosphosite } \\
\text { inhibition/blockage } \\
\text { by CIGB-300 impairs } \\
\text { IFN signaling }\end{array}$ & $\begin{array}{l}\text { Additive/Synergistic } \\
\text { profile of CIGB-300 } \\
\text { plus IFN alpha } \\
\text { (unpublished) }\end{array}$ & Unpublished \\
\hline $\begin{array}{l}\text { Phosphoproteome } \\
\text { overlap }\end{array}$ & $\begin{array}{l}\text { Host } \\
\text { Proteins }\end{array}$ & $\begin{array}{l}\text { MATR3, SQSTM1, } \\
\text { DID01 }\end{array}$ & $\begin{array}{l}\text { CIGB-300 Multitarget } \\
\text { effect impairing viral } \\
\text { transcription/splicing, } \\
\text { inflammation, } \\
\text { immunoresponse and } \\
\text { apoptosis }\end{array}$ & $\begin{array}{l}\text { Pulmonary lesions } \\
\text { resolution in CT } \\
\text { Phase I }\end{array}$ & $(14)$ \\
\hline $\begin{array}{l}\text { Kinase activity } \\
\text { profiles }\end{array}$ & $\begin{array}{l}\text { Host } \\
\text { proteins }\end{array}$ & SRPK1 (SRSF1,2,6,10) & $\begin{array}{l}\text { CIGB-300 impairs } \\
\text { Viral RNA splicing }\end{array}$ & $\begin{array}{l}\text { None, to be } \\
\text { evaluated in } \\
\text { preclincial seetings }\end{array}$ & NA \\
\hline $\begin{array}{l}\text { PPls vs H125 } \\
\text { Phosphoproteome }\end{array}$ & $\begin{array}{l}\text { Host } \\
\text { and } \\
\text { Viral } \\
\text { Proteins }\end{array}$ & $\begin{array}{l}\text { Several proteins (see } \\
\text { text and Fig. 7) } \\
\text { [LARP1,LARP7,LARP4B] }\end{array}$ & $\begin{array}{l}\text { CIGB-300 impairs } \\
\text { Viral RNA processing } \\
\text { and transcription }\end{array}$ & $\begin{array}{l}\text { None, to be } \\
\text { evaluated in } \\
\text { preclincial seetings }\end{array}$ & NA \\
\hline $\begin{array}{l}\text { SARS-CoV-2 vs } \\
\text { H125 } \\
\text { Phosphoproteome } \\
\text { overlap, Network } \\
\text { and Enrichment } \\
\text { analysis }\end{array}$ & $\begin{array}{l}\text { Host } \\
\text { proteins }\end{array}$ & $\begin{array}{l}\text { Several proteins (see } \\
\text { text and Fig. 8) } \\
\text { [HNRNPA1, HSPB1, } \\
\text { SRRM2, SRRM1, B23] }\end{array}$ & $\begin{array}{l}\text { CIGB-300 Multitarget } \\
\text { effect impairing on } \\
\text { mRNA metabolism } \\
\text { cell cycle and } \\
\text { Autophagy pathways }\end{array}$ & $\begin{array}{l}\text { Pulmonary lesions } \\
\text { resolution in CT } \\
\text { Phase I }\end{array}$ & $(14)$ \\
\hline $\begin{array}{l}\text { Human } \\
\text { Phenotypes }\end{array}$ & $\begin{array}{l}\text { Host } \\
\text { proteins }\end{array}$ & $\begin{array}{l}\text { HNPRNPA1, MATR3, } \\
\text { SQSTM1, B23, FIP1L1, } \\
\text { NUMA1 }\end{array}$ & $\begin{array}{l}\text { CIGB-300 might relief } \\
\text { COVID19 clinical } \\
\text { symptoms }\end{array}$ & $\begin{array}{l}\text { To be evaluated in } \\
\text { CT Phase II }\end{array}$ & NA \\
\hline
\end{tabular}

\section{Discussion}

Despite progress with the development and extensive use of vaccines, there is, so far, no definite effective therapeutic treatment against SARS-CoV2. The emergence of increasingly transmissible and aggressive mutated variants of the virus 
demands continuous efforts for discovering novel therapeutics to reduce the risk of patients to evolve to severe stages and death.

In this paper putative molecular mechanism are put forward to support the observed antiviral effects of CIGB-300 in coronavirus infections and the preliminary clinical results on preventing virus induced lung injury.

Targeting mechanisms of host cell, commonly hijacked by viruses to reproduce and spread, with consequent host cell functions damage, is a recognized strategy to confront present and future challenges of viral epidemics.

Phosphorylation is one of those mechanisms widely altered in human cell immediately after virus entry, contributing to the hijacking of multiple cellular processes.

We evidenced the potential incidence of CIGB-300 in SARS-CoV-2 induced N protein phosphorylation and localization that would alter $\mathrm{N}$ protein binding properties and its essential role in viral capsid assembly.

Coronavirus nucleocapsid $\mathrm{N}$ proteins play an essential role in virus cell cycle; its dimerization and binding to the viral genomic RNA is the first step for virion particle assembly. $\mathrm{N}$ protein is also involved in viral genomic RNA synthesis (84) and have been also identified as an antagonist of type I interferon signaling (42).

One distinguishing pattern of SARS-CoV-2 infection is a diminished transcriptional response of type I/III interferon-induced genes. These genes are relevant for the antiviral host response to virus infection. Orf6 is one of the viral proteins identified to have an antagonistic effect on this response, in particular its C-terminal end. We supported the likely binding of CIGB-300 to a CK2 phospho-acceptor site at residue Ser50 near its C-terminal end, which might contribute to restore IFN signaling.

SARS-CoV-2 infection is also characterized by the induction of cytokines responsible for a strong inflammatory response. SQSTM1 accumulation due to an increase in its phosphorylation levels plays an important role in airway inflammation and fibrosis. Binding of CIGB-300 to Ser272 of SQSTM1, might reduce the aggresome accumulation and consequently reduce lung damage in Covid-19 patients.

One of the mechanisms used for viruses to increase their replication and translation is the kidnapping of host proteins involved in RNA metabolism. As others have previously evidenced, our analysis of multiple phosphoproteomics studies also found these same phenomena in SARS-CoV-2 infected cells from the early stages of the infection. It is observed a significant increase of kinase activity involving CK2 phospho-acceptor sites in proteins involved in "mRNA Splicing" and "Processing of capped intron containing pre-mRNA". At the same time we identified several of these phosphor-acceptor sites to be inhibited by the action of CIGB-300. In particular several members of the SRSF family of proteins, which are essential splicing factors, are targeted by CIGB-300. This support the potential role of CIGB-300 in perturbing the kidnaping of host proteins at early stages of viral infection.

Our study revealed how the use of CIGB-300 may participate in attenuating some of the phenotypes frequently observed in Covid-19 patients, in particular those related to muscle, bleeding, coagulation and respiratory disorders.

We found some additional remarkable finding, once again surfacing B23 as a relevant player in a viral infection, now in the context of SARS-CoV-2. First, we saw it as the host protein with a higher correlation of expression to viral proteins, in particular to Orf6. Second, we identified B23 as a highly connected node in a network of proteins consistently upregulated by SARS-CoV2 infection and inhibited by CIGB-300, which is related to Cell Cycle pathway (Fig. 8). Third, it was part of a phenotype network related to respiratory, bleeding and coagulation disorders, symptoms widely reported in Covid-19 disease. Previously, Kondo et al. (85) showed that B23 inhibited the DNA-binding and transcriptional activity of interferon regulatory factor 1(IRF1), while Abe et al. (86) found that B23 regulates the expression of IFN-y-inducible genes and binds to transcription factors STAT1 and IRF1. Taken together, both Orf6 and B23 might play a role in the inhibitory effect of IFN signaling. 
On the other hand, it is known that post-translational modifications like phosphorylation are involved in the regulation of molecular chaperone activities (87). In particular CK2 phosphorylation was found to play an important role in B23 chaperon activity (88).

CIGB-300 might interfere B23 chaperon activity by inhibiting phosphorylation and perturbing its interactions with host and viral proteins. For instance, Orf6 localize in ER/Golgi membrane and NPC associated to KPNA2 and NUP98, respectively. May B23 chaperone activity play a role in SARS-CoV-2 infected cells by carrying Orf6 to the ER/Golgi membrane and the NPC?

Of note, the CIGB-300 peptide interacted with the B23 protein in MDKB cells infected with a Bovine Coronavirus strain (BCoV) (15). In these cells, also several host proteins participating in protein folding, populated the interactomic profile of the CIGB300 peptide. However, to definitively address any particular role of B23/NPM1 in the context of an ongoing coronavirus infection, gain- and/or lost-of-function genetic experiments need to be done.

In summary, we supported different hypothesis which need to be verified in suitable pre-clinical models (see Table 2). Notably, while our findings suggest a clear impact of CK2 inhibitors in viral replication and hijacking strategies, differences could be also inferred based on their particular inhibitory mechanism. For instance, the use of CIGB-300 to impair CK2-mediated signaling in cancer do not mirror CX-4945 effects in pre-clinical and clinical settings, thus the same could be expected in viral infections like those caused by coronaviruses. The fact that CIGB-300 targets both the CK2 enzyme and a subset of its substrates, may imply particular inhibitory effects of protein-protein interactions, as well as in the crosstalks with other nearby Post-translational

modifications sites (10); therefore, resulting into different molecular, cellular and organismal outcomes.

\section{Conclusions}

The current study predicts the interference of CIGB-300 in several SARS-CoV-2 infection-induced phosphorylation events that play a role in virus reproduction and spreading. CIGB-300 targets phosphor-acceptor site that are consistently up-regulated by SARS-CoV-2 infection. Our computational biology approach supports the potential impact of CIGB-300 in the treatment of Covid-19 patients, and encourages its clinical evaluation from early stages of the viral infection. Additional studies are needed to corroborate some of the proposed mechanism underlying the effect of CIGB-300 treatment in Covid-19 patients.

\section{Abbreviations}

GSEA:Gene set enrichment analysis; FDR:False Discovery Rate; NES: Normalized Enrichment Score; CES:Core enrichment set; PPI:Protein-Protein Interactions;NPM1/B23:Nucleophosmin; SRSF1:serine and arginine rich splicing factor 1; SRPK1: SRSF protein kinase 1; SQSTM1: sequestosome 1; HSPB1:heat shock protein family B (small) member 1; NF-kB:Nuclear factorkappa B; HNRNPA1:heterogeneous nuclear ribonucleoprotein A1; MATR3:matrin 3; DID01:death inducer-obliterator 1; KPNA1:karyopherin subunit alpha 1; KPNB1: karyopherin subunit beta 1;

\section{Declarations}

\section{Acknowledgements}

We thank Ricardo Javier Bringas for the design and drawing of figure 2.

\section{Author Contributions}

JM, RB and YP, Conceptualization and Investigation; JM and RB, Data curation, Formal Analysis and Writing - original draft; All authors, Methodology and Writing - review \& editing. RB and YP, Supervision. All authors reviewed the results and approved the final version of the manuscript.

Page $12 / 23$ 


\section{Funding}

The Center for Genetics Engineering and Biotechnology founded this work.

\section{Availability of data and materials}

All relevant data generated by authors are within the manuscript and its supplementary information files.

\section{Ethical approval and consent to participate}

Not applicable.

\section{Consent for publication}

Not applicable.

\section{Competing interests}

The authors declared no conflict of interest.

\section{Author information}

Ricardo Bringas Perez ${ }^{1}$, E-mail: ricardo.bringas@cigb.edu.cu

Jorge Fernandez-de-Cossio , E-mail: jorge.cossio@cigb.edu.cu

Yasser Perera-Negrin²,3, E-mail: ypereranegrin@ccbjic.com

${ }^{1}$ Department of Bioinformatics, Division of Informatics, Center for Genetic Engineering and Biotechnology, Havana, Cuba

${ }^{2}$ Laboratory of Molecular Oncology, Department of Pharmaceuticals, Division of Biomedical Research, Center for Genetic Engineering and Biotechnology, Havana, Cuba

${ }^{3}$ China-Cuba Biotechnology Joint Innovation Center, Yongzhou Zhong Gu Biotechnology Co., Yongzhou, Hunan, People Republic of China

\section{References}

1. Serafin MB, Bottega A, Foletto VS, da Rosa TF, Horner A, Horner R. Drug repositioning is an alternative for the treatment of coronavirus COVID-19. Int J Antimicrob Agents. 2020;55(6):105969.

2. Zhou Y, Wang F, Tang J, Nussinov R, Cheng F. Artificial intelligence in COVID-19 drug repurposing. The Lancet Digital health. 2020;2(12):e667-e76.

3. Zhou P, Yang XL, Wang XG, Hu B, Zhang L, Zhang W, et al. A pneumonia outbreak associated with a new coronavirus of probable bat origin. Nature. 2020;579(7798):270-3.

4. Blanco-Melo D, Nilsson-Payant BE, Liu WC, Uhl S, Hoagland D, Moller R, et al. Imbalanced Host Response to SARS-CoV-2 Drives Development of COVID-19. Cell. 2020;181(5):1036-45 e9.

5. Gordon DE, Jang GM, Bouhaddou M, Xu J, Obernier K, White KM, et al. A SARS-CoV-2 protein interaction map reveals targets for drug repurposing. Nature. 2020;583(7816):459-68.

6. Bouhaddou M, Memon D, Meyer B, White KM, Rezelj VV, Correa Marrero M, et al. The Global Phosphorylation Landscape of SARS-CoV-2 Infection. Cell. 2020;182(3):685-712 e19.

7. Recknor CP. Evaluating Safety, Pharmacokinetics and Clinical Benefit of Silmitasertib (CX-4945) in Subjects With Moderate COVID-19. 2020. 
8. Aguila JDFV, Jiménez YG, Sacerio ROR, Rodríguez AL, Fraga CRR, Silva YR, C. V.,. Safety of intravenous application of CIGB-300 in patients with hematological malignancies. EHPMA study.. Revista Cubana de Hematología, Inmunología y Hemoterapia 2016;32(2):236 - 48.

9. García-Diegues RdIT-S, Phase A. I Study of CIGB-300 Administered Intravenously in Patients with Relapsed/Refractory Solid Tumors. ARCHIVOS DE MEDICINA. 2018;1(1):4.

10. Perera Y, Ramos Y, Padron G, Caballero E, Guirola O, Caligiuri LG, et al. CIGB-300 anticancer peptide regulates the protein kinase CK2-dependent phosphoproteome. Molecular cellular biochemistry. 2020;470(1-2):63-75.

11. Perera Y, Farina HG, Gil J, Rodriguez A, Benavent F, Castellanos L, et al. Anticancer peptide CIGB-300 binds to nucleophosmin/B23, impairs its CK2-mediated phosphorylation, and leads to apoptosis through its nucleolar disassembly activity. Mol Cancer Ther. 2009;8(5):1189-96.

12. Nouri K, Moll JM, Milroy LG, Hain A, Dvorsky R, Amin E, et al. Biophysical Characterization of Nucleophosmin Interactions with Human Immunodeficiency Virus Rev and Herpes Simplex Virus US11. PloS one. 2015;10(12):e0143634.

13. Lobaina Y, Perera Y. Implication of B23/NPM1 in Viral Infections, Potential Uses of B23/NPM1 Inhibitors as Antiviral Therapy. Infect Disord Drug Targ. 2019;19(1):2-16.

14. Cruz LR, Baladron I, Rittoles A, Diaz PA, Valenzuela C, Santana R, et al. Treatment with an Anti-CK2 Synthetic Peptide Improves Clinical Response in COVID-19 Patients with Pneumonia. A Randomized and Controlled Clinical Trial. ACS Pharmacol TransI Sci. 2020;4(1):206-12.

15. Ramón AC, Pérez GV, Caballero E, Rosales M, Aguilar D, Vázquez-Blomquist D, et al. Targeting of Protein Kinase CK2 Elicits Antiviral Activity on Bovine Coronavirus Infection. bioRxiv: the preprint server for biology. 2021:2021.06.08.447588.

16. Hekman RM, Hume AJ, Goel RK, Abo KM, Huang J, Blum BC, et al. Actionable Cytopathogenic Host Responses of Human Alveolar Type 2 Cells to SARS-CoV-2. Molecular cell. 2020;80(6):1104-22 e9.

17. Klann K, Bojkova D, Tascher G, Ciesek S, Munch C, Cinatl J. Growth Factor Receptor Signaling Inhibition Prevents SARSCoV-2 Replication. Molecular cell. 2020;80(1):164-74. e4.

18. Stukalov A, Girault V, Grass V, Karayel O, Bergant V, Urban C, et al. Multilevel proteomics reveals host perturbations by SARS-CoV-2 and SARS-CoV. Nature. 2021;594(7862):246-52.

19. Pundir S, Martin MJ, O'Donovan C. UniProt Protein Knowledgebase. Methods Mol Biol. 2017;1558:41-55.

20. Bojkova D, Klann K, Koch B, Widera M, Krause D, Ciesek S, et al. Proteomics of SARS-CoV-2-infected host cells reveals therapy targets. Nature. 2020;583(7816):469-72.

21. Stark C, Breitkreutz BJ, Reguly T, Boucher L, Breitkreutz A, Tyers M. BioGRID: a general repository for interaction datasets. Nucleic Acids Res. 2006;34(Database issue):D535-9.

22. Hornbeck PV, Zhang B, Murray B, Kornhauser JM, Latham V, Skrzypek E. PhosphoSitePlus, 2014: mutations, PTMs and recalibrations. Nucleic Acids Res.43(Database issue):D512-20.

23. Thompson JD, Gibson TJ, Plewniak F, Jeanmougin F, Higgins DG. The CLUSTAL_X windows interface: flexible strategies for multiple sequence alignment aided by quality analysis tools. Nucleic Acids Res. 1997;25(24):4876-82.

24. Saeed Al, Bhagabati NK, Braisted JC, Liang W, Sharov V, Howe EA, et al. TM4 microarray software suite. Methods Enzymol. 2006;411:134-93.

25. Tusher VG, Tibshirani R, Chu G. Significance analysis of microarrays applied to the ionizing radiation response. Proc Natl Acad Sci USA. 2001;98(9):5116-21.

26. Mootha VK, Lindgren CM, Eriksson KF, Subramanian A, Sihag S, Lehar J, et al. PGC-1alpha-responsive genes involved in oxidative phosphorylation are coordinately downregulated in human diabetes. Nat Genet. 2003;34(3):267-73.

27. Subramanian A, Tamayo P, Mootha VK, Mukherjee S, Ebert BL, Gillette MA, et al. Gene set enrichment analysis: a knowledge-based approach for interpreting genome-wide expression profiles. Proc Natl Acad Sci USA.

2005;102(43):15545-50.

Page $14 / 23$ 
28. Subramanian A, Kuehn H, Gould J, Tamayo P, Mesirov JP. GSEA-P: a desktop application for Gene Set Enrichment Analysis. Bioinformatics. 2007;23(23):3251-3.

29. Shannon P, Markiel A, Ozier O, Baliga NS, Wang JT, Ramage D, et al. Cytoscape: a software environment for integrated models of biomolecular interaction networks. Genome Res. 2003;13(11):2498-504.

30. Smoot ME, Ono K, Ruscheinski J, Wang PL, Ideker T. Cytoscape 2.8: new features for data integration and network visualization. Bioinformatics. 2011;27(3):431-2.

31. Martin A, Ochagavia ME, Rabasa LC, Miranda J, Fernandez-de-Cossio J, Bringas R. BisoGenet: a new tool for gene network building, visualization and analysis. BMC Bioinformatics.11:91.

32. Jassal B, Matthews L, Viteri G, Gong C, Lorente P, Fabregat A, et al. The reactome pathway knowledgebase. Nucleic Acids Res.48(D1):D498-D503.

33. Tabas-Madrid D, Nogales-Cadenas R, Pascual-Montano A. GeneCodis3: a non-redundant and modular enrichment analysis tool for functional genomics. Nucleic Acids Res. 2012;40(Web Server issue):W478-83.

34. Maere S, Heymans K, Kuiper M. BiNGO: a Cytoscape plugin to assess overrepresentation of gene ontology categories in biological networks. Bioinformatics. 2005;21(16):3448-9.

35. Chang CK, Sue SC, Yu TH, Hsieh CM, Tsai CK, Chiang YC, et al. Modular organization of SARS coronavirus nucleocapsid protein. Journal of biomedical science. 2006;13(1):59-72.

36. Davidson AD, Williamson MK, Lewis S, Shoemark D, Carroll MW, Heesom KJ, et al. Characterisation of the transcriptome and proteome of SARS-CoV-2 reveals a cell passage induced in-frame deletion of the furin-like cleavage site from the spike glycoprotein. Genome medicine. 2020;12(1):68.

37. Surjit M, Kumar R, Mishra RN, Reddy MK, Chow VT, Lal SK. The severe acute respiratory syndrome coronavirus nucleocapsid protein is phosphorylated and localizes in the cytoplasm by 14-3-3-mediated translocation. J Virol. 2005;79(17):11476-86.

38. Chang MS, Lu YT, Ho ST, Wu CC, Wei TY, Chen CJ, et al. Antibody detection of SARS-CoV spike and nucleocapsid protein. Biochem Biophys Res Commun. 2004;314(4):931-6.

39. Zhang J, Cruz-Cosme R, Zhuang MW, Liu D, Liu Y, Teng S, et al. A systemic and molecular study of subcellular localization of SARS-CoV-2 proteins. Signal transduction targeted therapy. 2020;5(1):269.

40. Schneider WM, Chevillotte MD, Rice CM. Interferon-stimulated genes: a complex web of host defenses. Annu Rev Immunol. 2014;32:513-45.

41. Frieman M, Yount B, Heise M, Kopecky-Bromberg SA, Palese P, Baric RS. Severe acute respiratory syndrome coronavirus ORF6 antagonizes STAT1 function by sequestering nuclear import factors on the rough endoplasmic reticulum/Golgi membrane. J Virol. 2007;81(18):9812-24.

42. Li JY, Liao CH, Wang Q, Tan YJ, Luo R, Qiu Y, et al. The ORF6, ORF8 and nucleocapsid proteins of SARS-CoV-2 inhibit type I interferon signaling pathway. Virus Res. 2020;286:198074.

43. Yuen CK, Lam JY, Wong WM, Mak LF, Wang X, Chu H, et al. SARS-CoV-2 nsp13, nsp14, nsp15 and orf6 function as potent interferon antagonists. Emerging microbes infections. 2020;9(1):1418-28.

44. Lei X, Dong X, Ma R, Wang W, Xiao X, Tian Z, et al. Activation and evasion of type I interferon responses by SARS-CoV-2. Nature communications. 2020;11(1):3810.

45. Zeng $Y$, Ye L, Zhu S, Zheng H, Zhao P, Cai W, et al. The nucleocapsid protein of SARS-associated coronavirus inhibits B23 phosphorylation. Biochem Biophys Res Commun. 2008;369(2):287-91.

46. Franchin C, Cesaro L, Salvi M, Millioni R, lori E, Cifani P, et al. Quantitative analysis of a phosphoproteome readily altered by the protein kinase CK2 inhibitor quinalizarin in HEK-293T cells. Biochim Biophys Acta. 2015;1854(6):609-23.

47. Miorin L, Kehrer T, Sanchez-Aparicio MT, Zhang K, Cohen P, Patel RS, et al. SARS-CoV-2 Orf6 hijacks Nup98 to block STAT nuclear import and antagonize interferon signaling. Proc Natl Acad Sci USA. 2020;117(45):28344-54. 
48. Salton M, Elkon R, Borodina T, Davydov A, Yaspo ML, Halperin E, et al. Matrin 3 binds and stabilizes mRNA. PloS one. 2011;6(8):e23882.

49. Yamaguchi A, Takanashi K. FUS interacts with nuclear matrix-associated protein SAFB1 as well as Matrin3 to regulate splicing and ligand-mediated transcription. Scientific reports. 2016;6:35195.

50. Sarracino A, Gharu L, Kula A, Pasternak AO, Avettand-Fenoel V, Rouzioux C, et al. Posttranscriptional Regulation of HIV-1 Gene Expression during Replication and Reactivation from Latency by Nuclear Matrix Protein MATR3. mBio. 2018;9(6).

51. Hibino Y, Ohzeki H, Hirose N, Sugano N. Involvement of phosphorylation in binding of nuclear scaffold proteins from rat liver to a highly repetitive DNA component. Biochim Biophys Acta. 1998;1396(1):88-96.

52. Malik AM, Barmada SJ. Matrin 3 in neuromuscular disease: physiology and pathophysiology. JCl insight. 2021;6(1).

53. Johnson JO, Pioro EP, Boehringer A, Chia R, Feit H, Renton AE, et al. Mutations in the Matrin 3 gene cause familial amyotrophic lateral sclerosis. Nature neuroscience. 2014;17(5):664-6.

54. Zhang C, Gao J, Li M, Deng Y, Jiang C. p38delta MAPK regulates aggresome biogenesis by phosphorylating SQSTM1 in response to proteasomal stress. Journal of cell science. 2018;131(14).

55. Gao J, Li M, Qin S, Zhang T, Jiang S, Hu Y, et al. Cytosolic PINK1 promotes the targeting of ubiquitinated proteins to the aggresome-autophagy pathway during proteasomal stress. Autophagy. 2016;12(4):632-47.

56. Tran I, Ji C, Ni I, Min T, Tang D, Vij N. Role of Cigarette Smoke-Induced Aggresome Formation in Chronic Obstructive Pulmonary Disease-Emphysema Pathogenesis. Am J Respir Cell Mol Biol. 2015;53(2):159-73.

57. Wu Y, Jin Y, Sun T, Zhu P, Li J, Zhang Q, et al. p62/SQSTM1 accumulation due to degradation inhibition and transcriptional activation plays a critical role in silica nanoparticle-induced airway inflammation via NF-kappaB activation. Journal of nanobiotechnology. 2020;18(1):77.

58. Luciani A, Villella VR, Esposito S, Brunetti-Pierri N, Medina DL, Settembre C, et al. Cystic fibrosis: a disorder with defective autophagy. Autophagy. 2011;7(1):104-6.

59. Luciani A, Villella VR, Esposito S, Brunetti-Pierri N, Medina D, Settembre C, et al. Defective CFTR induces aggresome formation and lung inflammation in cystic fibrosis through ROS-mediated autophagy inhibition. Nat Cell Biol. 2010;12(9):863-75.

60. Garcia-Domingo D, Leonardo E, Grandien A, Martinez P, Albar JP, Izpisua-Belmonte JC, et al. DIO-1 is a gene involved in onset of apoptosis in vitro, whose misexpression disrupts limb development. Proc Natl Acad Sci USA. 1999;96(14):79927.

61. Lerebours F, Vacher S, Guinebretiere JM, Rondeau S, Caly M, Gentien D, et al. Hemoglobin overexpression and splice signature as new features of inflammatory breast cancer? Journal of advanced research. 2021;28:77-85.

62. Li J, Wang AS, Wang S, Wang CY, Xue S, Li WY, et al. Death-inducer obliterator 1 (DIDO1) silencing suppresses growth of bladder cancer cells through decreasing SAPK/JNK signaling cascades. Neoplasma. 2020;67(5):1074-84.

63. Xiao J, Zhang R, Peng J, Yang Z. BAP1 maintains chromosome stability by stabilizing DID01 in renal cell carcinoma. American journal of cancer research. 2020;10(5):1455-66.

64. Pinna LA. Protein kinase CK2: a challenge to canons. Journal of cell science. 2002;115(Pt 20):3873-8.

65. Rogan PK, Mucaki EJ, Shirley BC. A proposed molecular mechanism for pathogenesis of severe RNA-viral pulmonary infections. F1000Research. 2020;9:943.

66. Hagopian JC, Ma CT, Meade BR, Albuquerque CP, Ngo JC, Ghosh G, et al. Adaptable molecular interactions guide phosphorylation of the SR protein ASF/SF2 by SRPK1. Journal of molecular biology. 2008;382(4):894-909.

67. Mole S, Faizo AAA, Hernandez-Lopez H, Griffiths M, Stevenson A, Roberts S, et al. Human papillomavirus type 16 infection activates the host serine arginine protein kinase 1 (SRPK1) - splicing factor axis. J Gen Virol. 2020;101(5):523-32.

68. Li X, Manley JL. Inactivation of the SR protein splicing factor ASF/SF2 results in genomic instability. Cell. 2005;122(3):365-78. 
69. Ghosh G, Adams JA. Phosphorylation mechanism and structure of serine-arginine protein kinases. FEBS J. 2011;278(4):587-97.

70. Mylonis I, Giannakouros T. Protein kinase CK2 phosphorylates and activates the SR protein-specific kinase 1. Biochem Biophys Res Commun. 2003;301(3):650-6.

71. Park AM, Kanai K, Itoh T, Sato T, Tsukui T, Inagaki Y, et al. Heat Shock Protein 27 Plays a Pivotal Role in Myofibroblast Differentiation and in the Development of Bleomycin-Induced Pulmonary Fibrosis. PloS one. 2016;11(2):e0148998.

72. Wettstein G, Bellaye PS, Kolb M, Hammann A, Crestani B, Soler P, et al. Inhibition of HSP27 blocks fibrosis development and EMT features by promoting Snail degradation. FASEB journal: official publication of the Federation of American Societies for Experimental Biology. 2013;27(4):1549-60.

73. Nappi L, Aguda AH, Nakouzi NA, Lelj-Garolla B, Beraldi E, Lallous N, et al. Ivermectin inhibits HSP27 and potentiates efficacy of oncogene targeting in tumor models. J Clin Investig. 2020;130(2):699-714.

74. Caly L, Druce JD, Catton MG, Jans DA, Wagstaff KM. The FDA-approved drug ivermectin inhibits the replication of SARSCoV-2 in vitro. Antiviral research. 2020;178:104787.

75. Ahmed S, Karim MM, Ross AG, Hossain MS, Clemens JD, Sumiya MK, et al. A five-day course of ivermectin for the treatment of COVID-19 may reduce the duration of illness. International journal of infectious diseases: IJID : official publication of the International Society for Infectious Diseases. 2021;103:214-6.

76. Okumus N, Demirturk N, Cetinkaya RA, Guner R, Avci IY, Orhan S, et al. Evaluation of the effectiveness and safety of adding ivermectin to treatment in severe COVID-19 patients. BMC Infect Dis. 2021;21(1):411.

77. Akbar MR, Pranata R, Wibowo A, Lim MA, Sihite TA, Martha JW. The prognostic value of elevated creatine kinase to predict poor outcome in patients with COVID-19 - A systematic review and meta-analysis. Diabetes metabolic syndrome. 2021;15(2):529-34.

78. Chan KH, Farouji I, Abu Hanoud A, Slim J. Weakness and elevated creatinine kinase as the initial presentation of coronavirus disease 2019 (COVID-19). Am J Emerg Med. 2020;38(7):1548. e1- e3.

79. De Giorgio MR, Di Noia S, Morciano C, Conte D. The impact of SARS-CoV-2 on skeletal muscles. Acta myologica: myopathies cardiomyopathies : official journal of the Mediterranean Society of Myology. 2020;39(4):307-12.

80. Townsend L, Dyer AH, Jones K, Dunne J, Mooney A, Gaffney F, et al. Persistent fatigue following SARS-CoV-2 infection is common and independent of severity of initial infection. PloS one. 2020;15(11):e0240784.

81. Versace V, Sebastianelli L, Ferrazzoli D, Saltuari L, Kofler M, Loscher W, et al. Case Report: Myopathy in Critically III COVID19 Patients: A Consequence of Hyperinflammation? Front Neurol. 2021;12:625144.

82. Levi M, Iba T. COVID-19 coagulopathy: is it disseminated intravascular coagulation? Intern Emerg Med. 2021;16(2):30912.

83. Singh P, Schwartz RA. Disseminated intravascular coagulation: A devastating systemic disorder of special concern with COVID-19. Dermatol Ther. 2020;33(6):e14053.

84. Wu CH, Chen PJ, Yeh SH. Nucleocapsid phosphorylation and RNA helicase DDX1 recruitment enables coronavirus transition from discontinuous to continuous transcription. Cell Host Microbe. 2014;16(4):462-72.

85. Kondo T, Minamino N, Nagamura-Inoue T, Matsumoto M, Taniguchi T, Tanaka N. Identification and characterization of nucleophosmin/B23/numatrin which binds the anti-oncogenic transcription factor IRF-1 and manifests oncogenic activity. Oncogene. 1997;15(11):1275-81.

86. Abe M, Lin J, Nagata K, Okuwaki M. Selective regulation of type II interferon-inducible genes by NPM1/nucleophosmin. FEBS Lett. 2018;592(2):244-55.

87. Jovcevski B, Kelly MA, Rote AP, Berg T, Gastall HY, Benesch JL, et al. Phosphomimics destabilize Hsp27 oligomeric assemblies and enhance chaperone activity. Chem Biol. 2015;22(2):186-95.

88. Szebeni A, Hingorani K, Negi S, Olson MO. Role of protein kinase CK2 phosphorylation in the molecular chaperone activity of nucleolar protein b23. J Biol Chem. 2003;278(11):9107-15. 


\section{Figures}

NCA P SARS2 NCAP_CVHSA

NCAP SARS2 NCAP_CVHSA

NCAP SARS2 NCAP_CVHSA

NCAP_SARS2 NCAP_CVHSA

NCA P SARS2 NCAP_CVHSA

NCA P SARS2 NCAP_CVHSA

NCAP_SARS2 NCAP_CVHSA

NCA P SARS2 NCAP_CVHSA

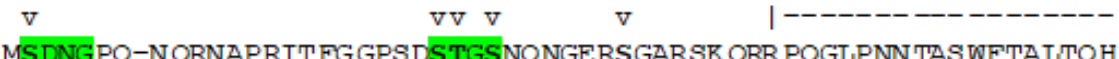
MSDNG PQ-N QRNAPRIT FG GPSDSTGSNQNGERS GARSR QRR PQGLPNN TAS WFTAITQH
MSDNG PQSN QRSAPRIT FG GPTDSTDNNQNGGRNGARPR QRRPQGLPNN TAS WFTAITQH

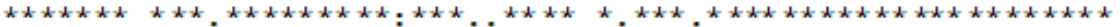

--------------- $\mathrm{v}-\mathrm{vv}----$ RNA binding domain $-\mathrm{v}^{----\mathrm{v}----------~}$ GREDLRFPR GQGVP INTNS SPDDQ I GYYR RATRRIRGGD GRMRDLSPRW YFY YLGTGPEA GREELRFPR GQGVP INTNS GPDDQIGYYR RATRRVRGGD GKMRELSPRW YFY YLGTGPEA

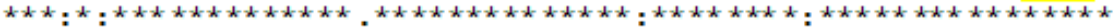

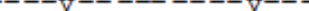
GLPYGANKD GIIWVATEGA INT PRDHI GT RNPANNAA IV LQL PQGTTLP RGF YAEGSRGG SL PYGANRE GIVWVATEGA INT PRDHI GT RNPNNNAATV LQL PQGTTLP RGF YAEGSRGG

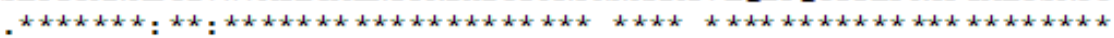

$\mathrm{V}--\mathrm{vV} \mid \mathrm{V} \mathrm{Vv} \quad \mathrm{V} \quad \mathrm{V} \quad \mathrm{VV} \quad \mathrm{VV} \quad \mathrm{Vv}$ SQASSRS SS RSRNSSRNST PGSSRGTS PA RMA GNGGDAALALLLLDRLNQLE SKMSGRGQ SQASSRSSS RSRGNSRNST PGSSRGNS PA RMASGGGETA LALLLLDRLNQIE SRVSGRGQ

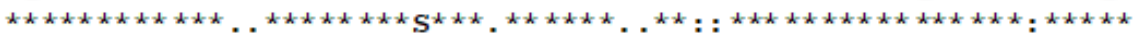
QQQGQTVTR KSAAEASRRP RQRRTATKQY NVTQAFGRRG PEQTQGNFGD QDL IRQGTDYK

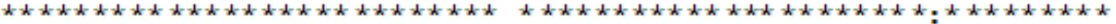

Dimerization domain

HWPQIAQFA PSA.SA FFGMS RIGMEVTP SG TWLTYTGA IK LDD RD PNFKD QVI LLNKHIDA HW PQIAQFA PSA.SAFFGMS RIGMEVTP SG TWLTYHGA IR LDDRD PQFRDNVI LLNRHIDA

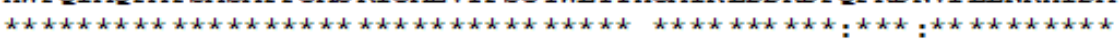
$-1 \quad v \quad v \quad v \quad v \quad v 0$ YKTFP PTEP KRDKRKRADE TQALPQRQKR QQTVTLLPAA DLD DFSKQLQQSMS--SADST YKTFP PTEP KKDKKRKTDE AQPLPQRQRK QPTVTLIPAA DMDDFSRQLQNSMSGASADST

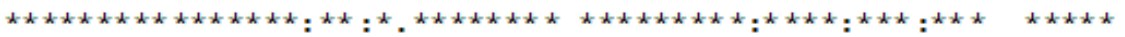

\section{Figure 1}

Sequence alignment of nucleocapside proteins of SARS-CoV-2 (NCAP_SARS2) and SARS-CoV (NCAP_CVHSA) viruses. Numbers at the right end indicate amino acids position in the SARS-CoV-2 protein. Above the aligned sequences the RNAbinding (residues 41-186, according to UniProt annotation) and Dimerization (residues 258-361) domains are delimited. vabove aminoacid residues indicates phosphorylation sites identified in the works of Davidson et al. (36), Bouhaddou et al. (6), Klann et al. (17) and Hekman et al. (16). Highlighted are the segment between a CK2 phospho-acceptor site and position +3 , in yellow those in silico predicted by Surjit et al. (37) and in green those experimentally validated by Davidson et al. (36). 


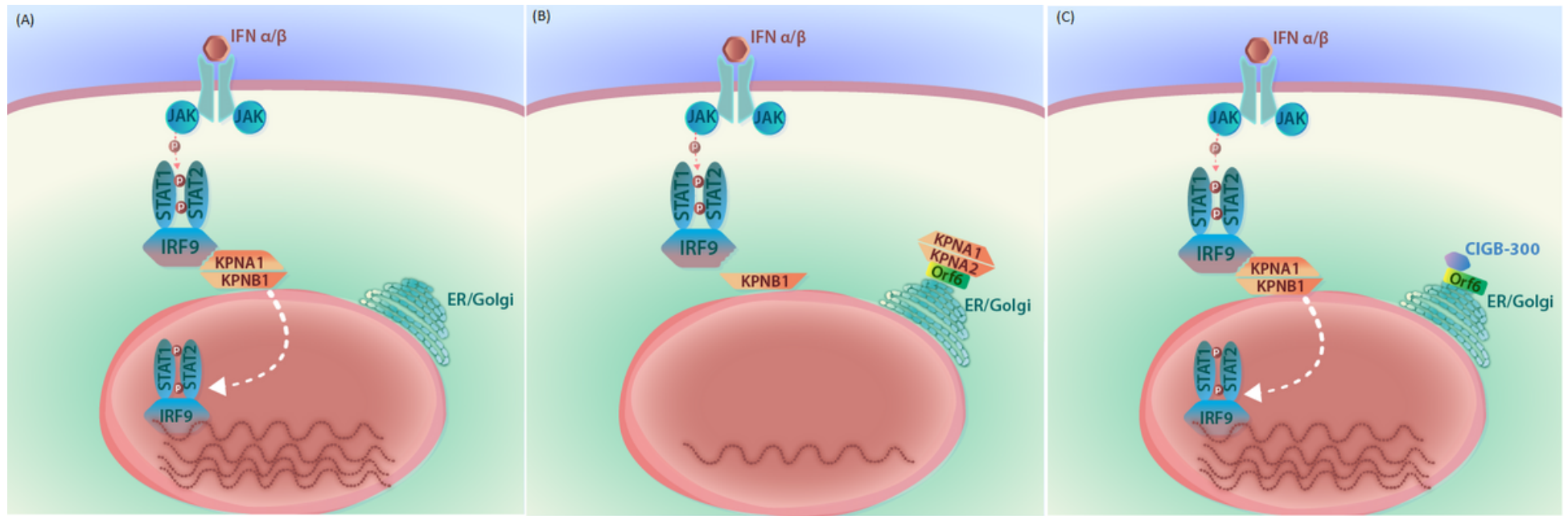

\section{Figure 2}

Sequence alignment of nucleocapside proteins of SARS-CoV-2 (NCAP_SARS2) and SARS-CoV (NCAP_CVHSA) viruses. Numbers at the right end indicate amino acids position in the SARS-CoV-2 protein. Above the aligned sequences the RNAbinding (residues 41-186, according to UniProt annotation) and Dimerization (residues 258-361) domains are delimited. vabove aminoacid residues indicates phosphorylation sites identified in the works of Davidson et al. (36), Bouhaddou et al. (6), Klann et al. (17) and Hekman et al. (16). Highlighted are the segment between a CK2 phospho-acceptor site and position +3 , in yellow those in silico predicted by Surjit et al. (37) and in green those experimentally validated by Davidson et al. (36).

$$
\begin{array}{lllll}
10 & 20 & 30 & 40 & 50
\end{array}
$$

NS6_CVHSA MFHLVDFQVTIAEILIIIMRTFRIAIWNL DVI ISSIVRQ LFK PLTKKNY SEL DDEE PME LD YP

NS6_SARS 2 MFHLVDFQVTIAEI LLI IMRTF KVSIWNL DYI INLI I KN LSKSLTEN KY SQL DEEQPME ID --

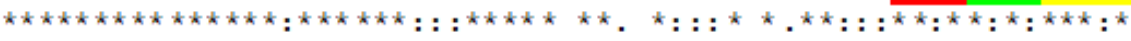

\section{Figure 3}

Sequence alignment of Orf6 proteins of SARS-CoV-2 (NS6_CVHSA) and SARS-CoV-2 (NS6_SARS2) viruses. Highlighted in red, green and yellow are the residues that were replaced by alanines in the mutants generated by Frieman et al. (41) and Lei et al. (44).

(A)

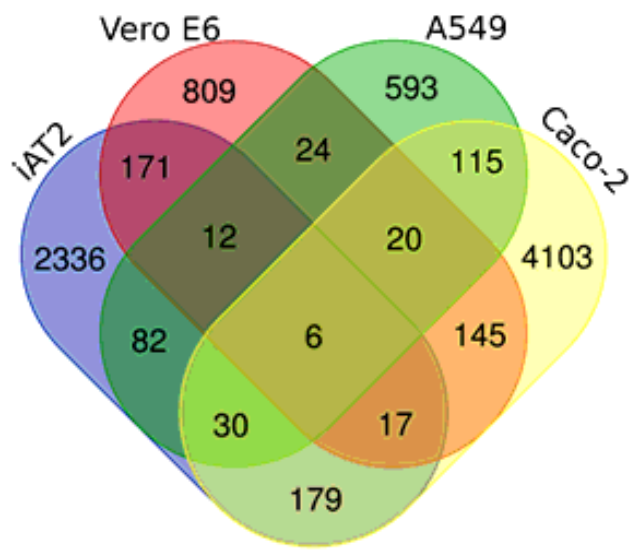

(B)

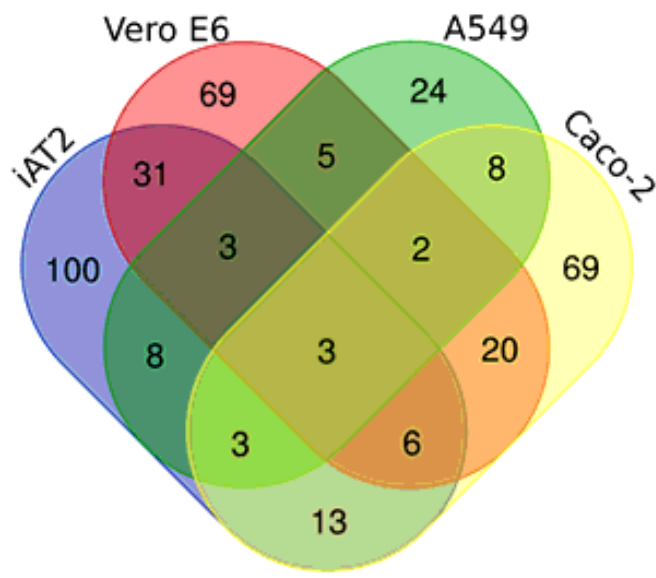

Figure 4 
Up regulated phosphorylation sites by SARS-CoV-2 infection and its intersection with CIGB-300 downregulated phosphoacceptor sites. A. Venn diagram showing unique phosphorylation sites identified as UP regulated in A549, VeroE6, iAT2 and Caco-2 cell lines. B. Venn diagram showing unique phosphorylation sites identified as UP regulated in A549, VeroE6, iAT2 and Caco- 2 cells and DOWN regulated by the action of CIGB-300 in H125 cell line.
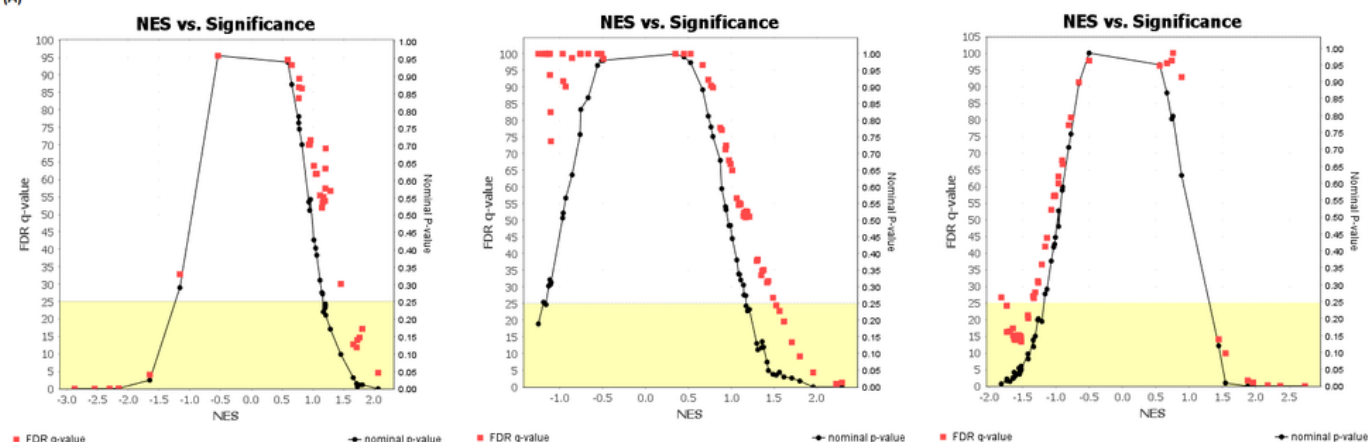

(B)
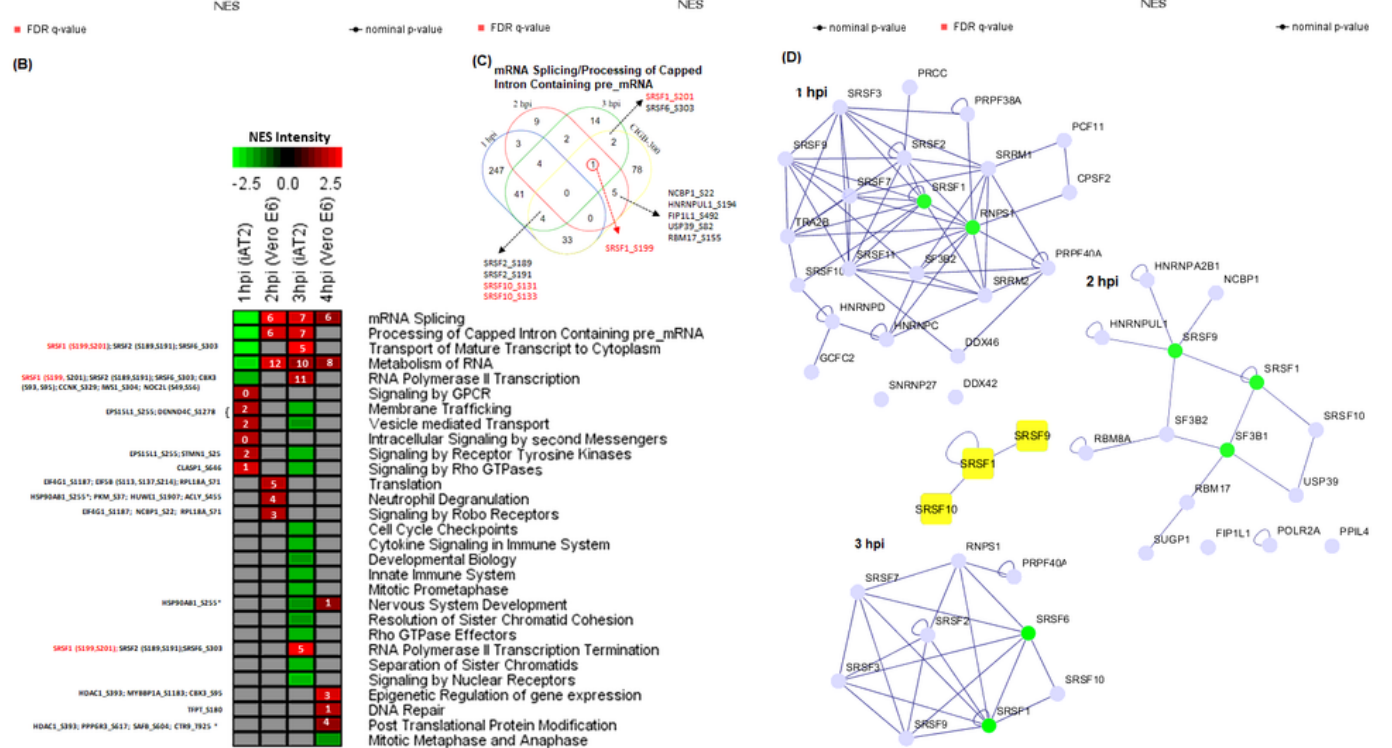

= FDR qualue

(E)
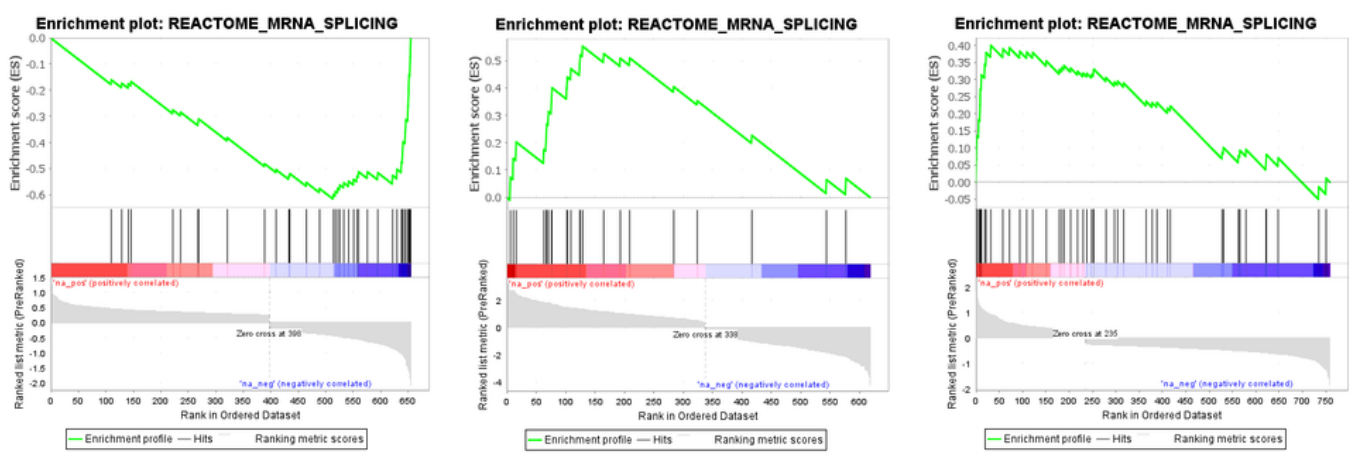

\section{Figure 5}

GSEA analysis of Reactome pathways of proteins with altered phosphorylation in early stages of infection. A. NES vs.

Significance plot of Reactome pathways generated by GSEA at $1 \mathrm{~h}, 2 \mathrm{~h}$ and $3 \mathrm{~h}$ post infection. The FDR q-value of a pathway is plotted with a red box, while the corresponding p-value is plotted with a black box. B. Heat map of the NESs of Reactome pathways resulted from GSEA analysis. The four columns corresponds to $1 \mathrm{~h}$ and $3 \mathrm{~h}$ time points of iAT2 cell (16) and $2 \mathrm{~h}$ and $4 \mathrm{~h}$ time points of Vero E6 cells (6) after infection by SARS-CoV-2. The numbers in small rectangles of the heat map indicate the number of proteins in the CES that contain phosphosites upregulated by SARS-CoV-2 infection and inhibited by CIGB300 (10). C. Venn diagram for sets of phosphorylation sites of proteins in the CES for "mRNA Splicing/Processing of capped intron containing pre-mRNA" 


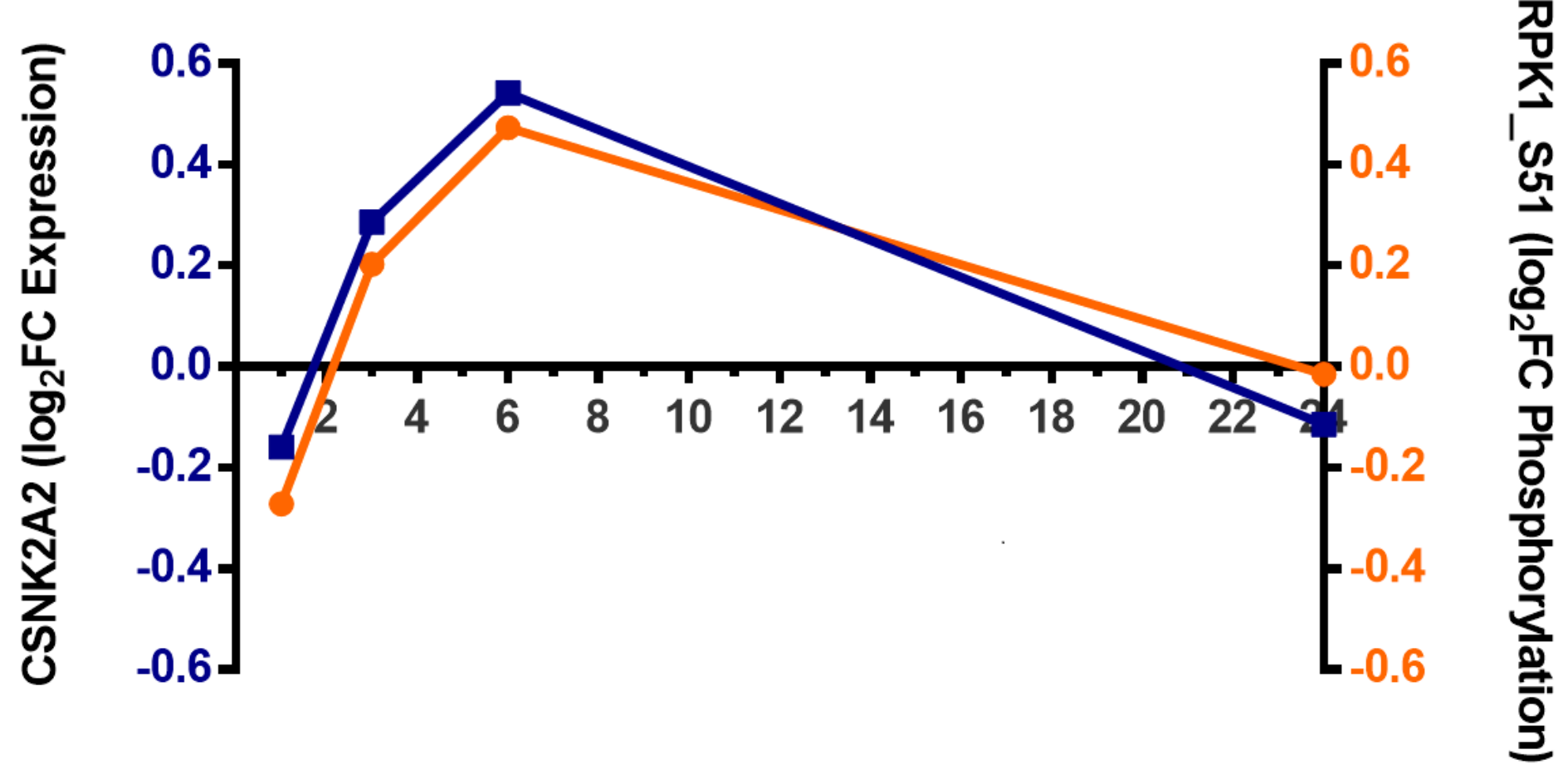

Figure 6

CK2 expression and SRKP1_S51 site phosphorylation profiles.
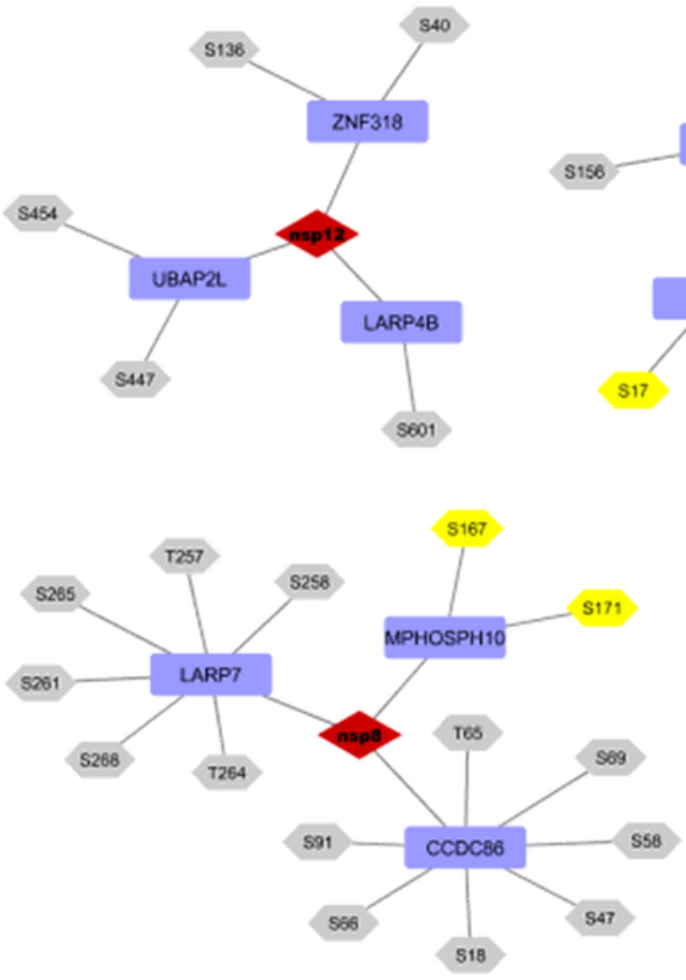
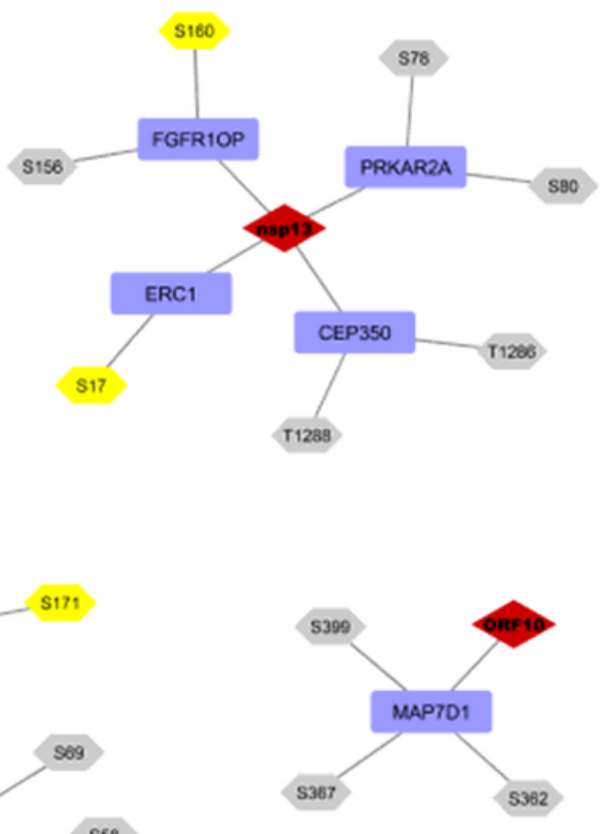

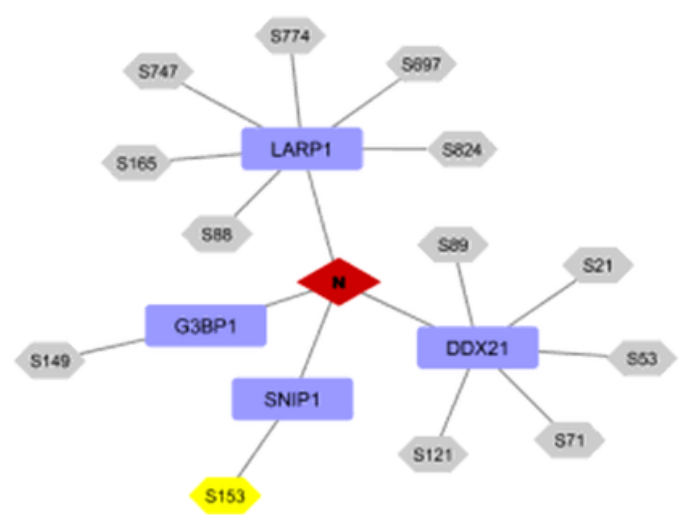

Figure 7 
Viral protein interactions with host proteins with phosphorylation sites inhibited by CIGB-300. Rhombus in red represents viral proteins, rectangles in blue represent host proteins, hexagons represent phospho-acceptor sites. In yellow are shown those sites whose phosphorylation was increased by SARS-CoV-2 infection.

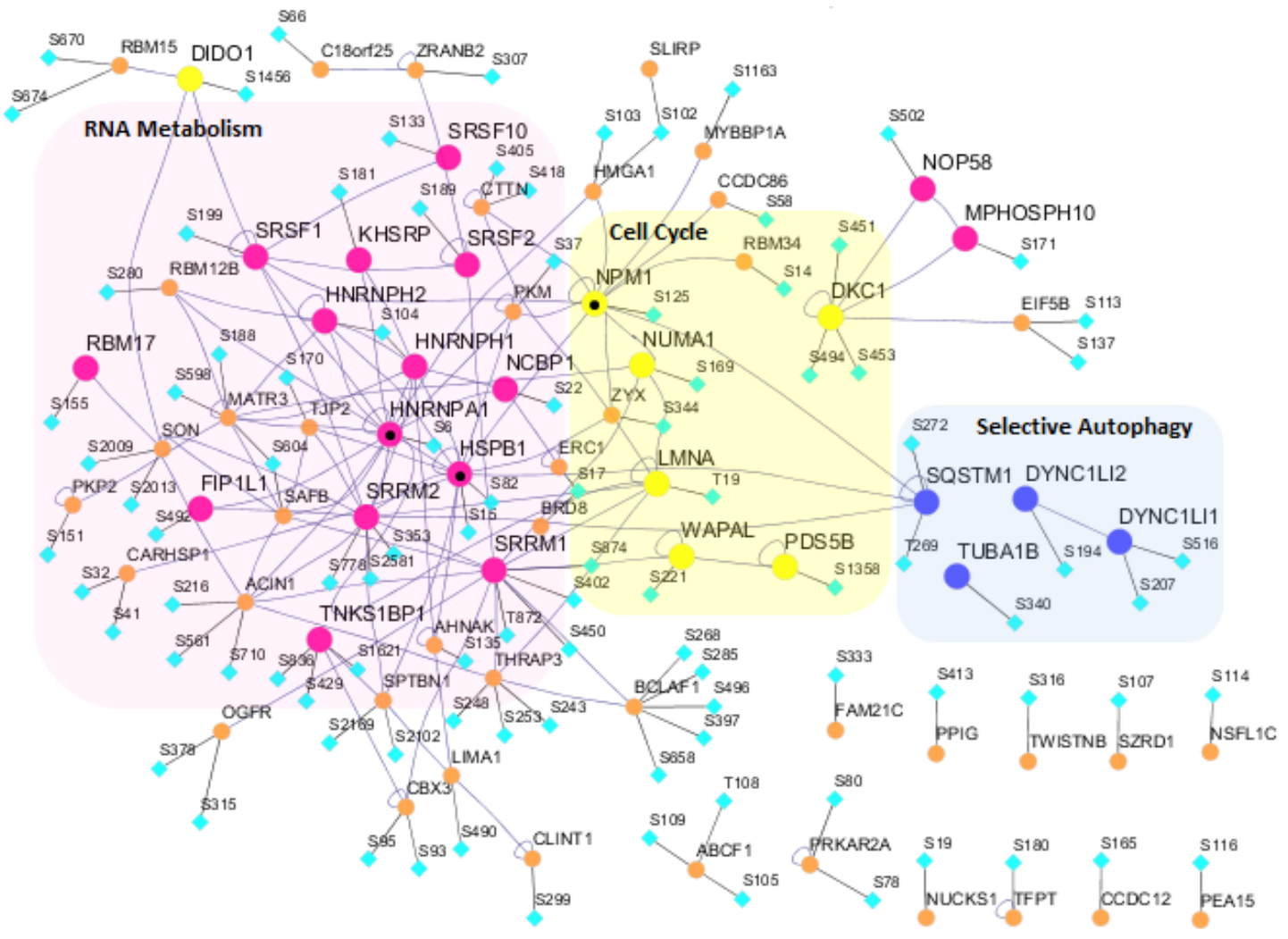

Figure 8: Network of proteins with phosphosites activated in at least two SARS-

CoV-2 studies and inhibited by CIGB-300. For each protein the phospho-acceptor

sites inhibited by CIGB-300 are shown. Proteins involved in more significant pathway

are grouped and colored: mRNA metabolism( $\bullet$ ), Cell Cycle( $)$ and 'Selective Autophagy'

(•). The five nodes with a higher degree (HNRNPA1, HSPB1, SRRM2, NPM1 and

SRRM1) are labeled with $(\bullet)$.

\section{Figure 8}

"See image above for figure legend" 


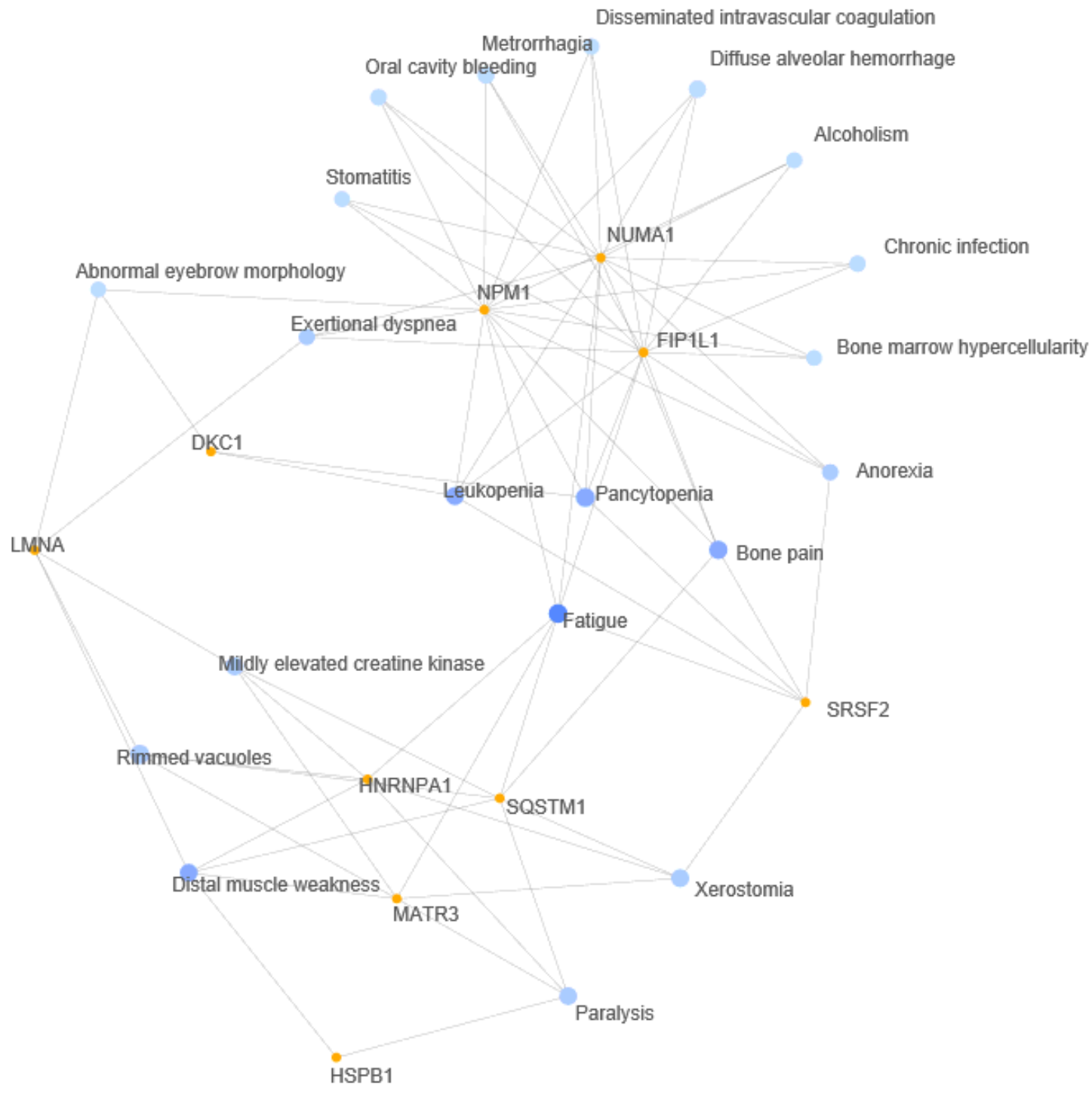

Figure 9

Network of enriched phenotypes in proteins with phosphosites activated in at least two SARS-CoV-2 studies and inhibited by CIGB-300. Genecodis functional annotation tool was used for the enrichment analysis and to generate the network of the top 20 enriched phenotypes. Nodes in blue represents enriched phenotypes and nodes in orange represent proteins associated to these phenotypes.

\section{Supplementary Files}

This is a list of supplementary files associated with this preprint. Click to download.

- AdditionalFile1Tables1.pdf

- AdditionalFile2Figs1.pdf

- AdditionalFile3Tables2.pdf

- AdditionalFile4Tables3.pdf

- AdditionalFile5Tables4.pdf 